\title{
The "I," the "We," and the "When": A Meta-Analysis of Motivational Primacy in Self-Definition
}

\author{
Lowell Gaertner \\ University of Tennessee
}

Jack L. Vevea

University of North Carolina at Chapel Hill

\author{
Constantine Sedikides \\ University of Southampton
}

Jonathan Iuzzini

Texas A\&M University

\begin{abstract}
What is the primary motivational basis of self-definition? The authors meta-analytically assessed 3 hypotheses: (a) The individual self is motivationally primary, (b) the collective self is motivationally primary, and (c) neither self is inherently primary; instead, motivational primacy depends on which self becomes accessible through contextual features. Results identified the individual self as the primary motivational basis of self-definition. People react more strongly to threat and enhancement of the individual than the collective self. Additionally, people more readily deny threatening information and more readily accept enhancing information when it pertains to the individual rather than the collective self, regardless of contextual influences. The individual self is the psychological home base, a stable system that can react flexibly to contextual influences.
\end{abstract}

The right of nature ... is the liberty each man hath to use his own power, as he will himself, for the preservation of his own nature; that is to say, of his own life.

$$
\text { —Thomas Hobbes, Leviathan }
$$

I only regret that I have but one life to lose for my country.

$$
\text { -Nathan Hale, spoken at his death }
$$

The self is in a continual process of construction, it cannot be adequately made up excepting in terms of the content which it supplies for the situation in which the agent has to act.

—John Dewey, Lectures on Psychological and Political Ethics

This article is concerned with a fundamental issue in psychology, education, social sciences, and humanities: Does the self-concept have a motivational hierarchy? Do all selves (i.e., self-definitions) have equal motivational potential? Which selfdefinition is motivationally primary?

We distinguish among three theoretical approaches to the issue. The first approach, one example of which is Hobbes's statement, posits that the individual self is motivationally primary. The second approach, exemplified by Hale's proclamation, maintains that the collective self is motivationally primary. The third approach advocates that neither self is inherently primary. Instead, the self that is more accessible through situational or contextual influences

Lowell Gaertner, Department of Psychology, University of Tennessee; Constantine Sedikides, Department of Psychology, University of Southampton, Southampton, England; Jack L. Vevea, Department of Psychology, University of North Carolina at Chapel Hill; Jonathan Iuzzini, Department of Psychology, Texas A\&M University.

We thank William Graziano, Vaida Thompson, and Wendy Wood for their comments on drafts of this article.

Correspondence concerning this article should be addressed to Lowell Gaertner, Department of Psychology, University of Tennessee, Knoxville, Tennessee 37996-0900. E-mail: gaertner@utk.edu is motivationally primary-a proposition that is in spirit with Dewey's thinking.

We articulate the three theoretical approaches and review relevant research. We argue that, when considered alone, each approach appears to be supported. However, independent tests, per se, tell only part of the story. Comparative tests provide a more refined solution to the problem. We report a meta-analysis of empirical studies relevant to the issue of relative motivational status.

\section{Will the Motivationally Primary Self Please Stand Up?}

Both the individual and the collective self are vital components of a person's self-concept. However, these two cognitive representations are relatively distinct and autonomous (Brewer \& Gardner, 1996; Deaux, 1996; Trafimow, Triandis, \& Goto, 1991). The individual self consists of those attributes that render the person unique from fellow in-group members; this type of self is independent of group membership. The collective self, on the other hand, is composed of attributes that are shared with in-group members; this self-definition derives from group membership. Indeed, the collective self is the embodiment of the group in the self (E. R. Smith \& Henry, 1996; Tajfel \& Turner, 1979; Turner, Hogg, Oakes, Reicher, \& Wetherell, 1987).

Even a cursory review of the literature provides a strong rationale for the theoretical view that the individual self is motivationally primary. We refer to this position as the individual-selfprimacy hypothesis (Gaertner, Sedikides, \& Graetz, 1999). From an evolutionary standpoint, the individual self is considered the unit of natural selection (Dawkins \& Krebs, 1978; Sedikides \& Skowronski, 1997; Wallace, 1973). From a developmental perspective, the core attributes of the individual self are remarkably stable across situations (Bem \& Allen, 1974; Markus, 1977; Sedikides, 1995), relatively short time intervals (Pelham, 1991; Pelham \& Wachsmuth, 1995, Study 1), and, indeed, the life span 
(Caspi \& Roberts, 2001; McCrae \& Costa, 1994; Schuerger, Tait, \& Tavernelli, 1982). Stability prevails even in the midst of change: When self-conceptions change, they do so slowly and in a predictable and orderly course (Damon \& Hart, 1986; Deutsch, Ruble, Brooks-Gunn, Flemming, \& Stangor, 1988; Mortimer, Finch, \& Kumka, 1982). Stability is maintained partly because the individual self both is vigorously defended against threatening feedback (Crocker \& Major, 1989; Sedikides \& Strube, 1997; S. E. Taylor $\&$ Brown, 1988) and selectively pursues and assimilates verifying or confirming information (Dunning, 1999; Greenwald, 1980; Swann, 1990).

On the other hand, a cursory review of the literature also offers a compelling rationale for the theoretical viewpoint that the collective self is motivationally primary. We refer to this viewpoint as the collective-self-primacy hypothesis (Gaertner et al., 1999). Group-level theories of evolution (Bulmer, 1978; Sober, 1980; Wilson \& Sober, 1994) propose that natural selection acts on the group as well as on the individual of a given species. Fit populations replace less fit populations. Consequently, natural selection favors traits that maintain the welfare of the collective. Another perspective on human evolution regards the social group as the primary environment for selection at the individual level (Brewer \& Caporael, 1990; Caporael, 1997; Caporael \& Baron, 1997). The social group provides the individual with shared resources, information, and protection from predators. Thus, individuals possessing the capacities for group life (e.g., a cooperative social orientation, group loyalty) have a better chance of survival than do individuals less suited for group life. An additional argument in favor of the collective-self-primacy hypothesis is that this type of self maintains cross-situational importance. According to optimal distinctiveness theory (ODT; Brewer, 1991; Brewer \& Roccas, 2001), self-definition fluctuates between the individual and the collective self as a means of satisfying the competing needs for assimilation (i.e., fitting in the group) and differentiation (i.e., being unique). ODT contends that the collective self provides the optimal level of self-definition. Unlike the individual self, the collective self maximizes assimilation and differentiation through intragroup and intergroup comparisons, respectively.

To complicate matters further, a strong rationale can be offered in conjunction with a third perspective, the contextual-primacy hypothesis (Gaertner et al., 1999). According to this perspective, neither the individual nor the collective self is inherently primary; instead, primacy is fleeting, is defined in terms of the accessibility of each self, and varies as a function of contextual influences. The rationale for this perspective derives mainly from two bodies of work. Markus and colleagues (Markus \& Kunda, 1986; Markus \& Wurf, 1987) conceptualized the self-concept as a collection of both chronically and momentarily accessible attributes. Behavior is regulated by the particular subset of self-attributes that is used to define the self at any given moment (i.e., the working selfconcept). The working self-concept can, in principle, be either the sum total of attributes that constitute the individual self or the sum total of attributes that constitute the collective self. Which self is accessible and more likely to influence behavior depends on contextual influences. Self-categorization theory (SCT; Turner et al., 1987; Turner, Oakes, Haslam, \& McGarty, 1994) also posits a malleable self-concept. However, SCT rejects the proposition of a structured self-concept in which stable self-attributes underlie context-dependent self-attributes. According to SCT, selfdefinition is fluid and depends on the contrasts provided by the social context. Self-attributes remain stable to the extent to which the social context remains stable. On the basis of the principle of metacontrast (i.e., social categories become salient to the extent to which the average perceived difference between aggregates of stimuli exceed the average perceived difference within the aggregates of stimuli; Hogg \& Turner, 1987; Turner et al., 1987), self-definition fluctuates toward the collective self in intergroup contexts and toward the individual self in intragroup contexts. (For another contextual statement, see Lewis, 2001.)

Each of the three theoretical approaches appears to be valid in its own right. That is, each hypothesis, when considered alone, appears to be buttressed by a web of social theory. Recognizing that there is inherent confirmation bias in single-theory testing, a belief shared by many scholars and philosophers of science (Gould, 1981; Lakatos, 1970; Mahoney, 1977; Platt, 1964; Rosenthal, 1966; Westfall, 1973), we suggest that the optimal approach to the issue of motivational primacy is comparative testing: Pit the hypotheses head to head and test which best accounts for the data.

Given that the interplay between the individual and the social group has occupied a central position in the social sciences and humanities, it is surprising that only one set of studies has been explicitly designed to provide a comparative test of the three hypotheses (Gaertner et al., 1999). The results of those studies offered compelling support to the individual-self-primacy hypothesis. Relative to persons whose collective self was threatened, persons whose individual self was threatened considered the threat more severe, experienced a more negative mood state, reported more anger, and derogated more fervently the source of the threat. These effects were obtained even when contextually relevant variables (e.g., level of group identification, the accessibility of the selves) were controlled and even when potential confounding variables (e.g., relative importance of the domain of threat) were controlled.

Given the breadth of the issue of motivational primacy, one set of studies hardly suffices to conclusively address the issue. Skeptics could easily argue that the finding of individual-self primacy is limited to the particular procedures, forms of threat, or social groups that the primary investigation used. One method to address this valid criticism is an endless, assembly-line-like array of studies that substitute various procedures, threats, and social groups. An alternative and perhaps more interesting solution (which is not too far removed from the assembly-line method) is to search the existing literature for empirical research that is relevant to the primacy issue although not necessarily designed to test it. Those relevant studies could be meta-analytically synthesized to provide further comparative tests of the three hypotheses. In this article, we address the primacy issue through a meta-analytic integration. We aspire, however, to accomplish more than a conceptual replication across various study characteristics. In addition to examining the issue of motivational primacy in the domain of threat, we expand the analysis and explore comparative reactions of the individual and collective self in the domain of enhancement. That is, we meta-analytically explore the issue of motivational primacy in two domains of motivation: threat and enhancement. More important, we conducted the meta-analysis using a random-effects model, which directly tests whether the results generalize to other possible studies that differ in regard to the characteristics and procedures of the synthesized studies. 


\section{The Present Meta-Analysis: Conceptual Issues}

We proceed with clarification of several conceptual issues. First, let us consider the individual-self-primacy and collective-selfprimacy hypotheses. We reasoned that motivational primacy most likely is manifested when the integrity of a given self is threatened or enhanced. That is, the more primary self more readily accepts positive information while more vociferously denying negative information and thus elicits stronger responses to threat or enhancement as compared with the self of lesser primacy (K. W. Campbell \& Sedikides, 1999; Sedikides \& Gaertner, 2001a). The experiments included in the meta-analysis modeled threat and enhancement by (a) directing unfavorable or favorable feedback to either the individual or the collective self or (b) assessing (e.g., by a trait-rating task) the extent to which persons associate and dissociate positive or negative information with the individual or collective self. Ideally, we would have treated threat versus enhancement as a moderating variable. However, the majority of experiments varied threat versus enhancement as a within-subject factor. Thus, to avoid problems associated with lack of statistical independence, we analyzed separately the effects from threat and enhancement.

Additionally, we needed to take into consideration the possibility of contextual sensitivity, as anticipated by the contextualprimacy hypothesis. Hence, we encoded as a meta-analytic study attribute a two-level factor, termed identification (low vs. high). This factor reflected the momentary salience and relevance for self-definition of the individual versus the collective self. As an example, identification is high to the extent that the social group is used momentarily as a meaningful source of self-definition (Abrams, 1994; Branscombe \& Wann, 1994; Spears, Doosje, \& Ellemers, 1997). In some cases, the level of identification was taken directly from the design of the primary experiment. In other cases, we inferred the level of identification on the basis of the metacontrast principle of SCT. To restate this principle as it applied to coding practices, intergroup contexts increase the salience of the collective self and engage identification with the in-group, whereas intragroup contexts increase the salience of the individual self and disengage identification with the in-group. In line with the metacontrast principle, we coded effects from intergroup contexts as high identification and coded effects from intragroup contexts as low identification. Consequently, we included as a second design factor in the meta-analysis the question of how identification was determined (determinant: authors of primary experiment vs. authors of current meta-analysis). We also allowed for the possibility of an interaction between identification and determinant.

We included as a second contextual moderator the type of group on which the collective self was based. Some experiments established transient groups in the laboratory through a variant of the minimal-group paradigm (Tajfel, 1969). Other experiments used natural social groups (e.g., political party membership, sorority or fraternity affiliation). Minimal and natural groups differ in several respects (Ostrom \& Sedikides, 1992). For example, participants may be more committed to and invested in natural groups. Also, unlike members of minimal groups, who are typically assigned to their group by experimenters, members of natural groups often voluntarily choose their group membership. Consequently, we coded as a meta-analytic study attribute a two-level factor that represented the type of group used in the primary experiment (group type: minimal group vs. natural group).

In the meta-analysis, we included only experiments that directed feedback (threat or enhancement) separately to the individual and collective self (see Inclusion Criteria). When directing feedback to the collective self, some experiments used procedures that explicitly and exclusively targeted the collective self. That is, feedback to the collective self conveyed no information about the individual self. Other experiments, however, used procedures that did not necessarily convey feedback exclusively to the collective self. For example, Jaffe and Yinon (1979) formed three-person groups and provided the group with insulting performance feedback. In this situation, participants could interpret the insult as a threat to their individual self (e.g., "I did poorly") in addition to their collective self (e.g., "My group did poorly"). As another example, some experiments used a repeated measures trait-rating task in which participants rated the descriptiveness of the individual self and collective self on positive and negative traits. In such experiments, participants might have considered whether a given trait described the individual self while determining whether the trait described the group. The potential consequence of this procedural confound would be to increase the magnitude of the participants' response relative to situations in which feedback was directed solely to the collective self. To assess this potential confound, we coded as a meta-analytic study attribute a two-level factor representing whether the primary experiment used procedures that unambiguously unconfounded feedback regarding the collective self from feedback regarding the individual self. We excluded from the meta-analysis studies that simultaneously and explicitly directed feedback to both selves and, therefore, unambiguously confounded feedback to the two selves (see Inclusion Criteria).

\section{Predictions Derived From the Three Hypotheses}

Each hypothesis predicts a unique pattern of results. According to the individual-self-primacy hypothesis, participants will react more strongly to threat or enhancement of the individual than the collective self and will more readily accept enhancing information and deny threatening information when the information pertains to the individual than the collective self. For example, threatening information will produce affective states that are more negative and enhancing information will produce affective states that are more positive when the information pertains to the individual rather than the collective self.

The collective-self-primacy hypothesis, on the other hand, anticipates the opposite pattern of results. Participants will react more strongly to threat or enhancement of the collective than the individual self and will more readily accept enhancing information and deny threatening information when the information pertains to the collective as opposed to the individual self. For example, threatening information will produce affective states that are more negative and enhancing information will produce affective states that are more positive when the information pertains to the collective rather than the individual self.

The contextual-primacy hypothesis predicts yet another pattern of results. Primacy will vary with contextual factors such as identification and group type (i.e., minimal vs. natural group). The pattern predicted by the collective-self-primacy hypothesis will be evidenced to the extent to which participants identify strongly with the group or when the collective self is derived from a natural 
group. On the other hand, the pattern predicted by the individualself-primacy hypothesis will be evidenced to the extent to which participants identify weakly with the group or when the collective self is derived from a laboratory-induced minimal group. Stated otherwise, the relative reaction of the individual and collective self to threatening and enhancing information will be moderated by identification and group type.

\section{A Consideration of the Relative Potency of Threat and Enhancement}

The three hypotheses, broadly stated, predict that self-definitional primacy will be revealed in the case of both threat and enhancement and, therefore, assume that threat and enhancement are equally potent motives. There are reasons, however, to be circumspect about this assumption.

The asymmetric S-shaped value function of prospect theory indicates that response to potential loss is more extreme than response to potential gain (Kahneman \& Tversky, 1979; Tversky \& Kahneman, 1986). That is, losses loom larger than gains. Furthermore, attributions and information processing are more biased in the face of threat than of enhancement (K. W. Campbell \& Sedikides, 1999; Sedikides \& Green, 2000; S. E. Taylor, 1991). Indeed, negative information affects evaluations more strongly than does positive information (Baumeister, Bratslavsky, Finkenauer, \& Vohs, 2001; Rozin \& Royzman, 2001; Sedikides \& Skowronski, 1993). Negative stimuli are weighed more heavily in the brain, as they register larger amplitude late positive brain potentials than do either positive or neutral stimuli (Ito, Larsen, Smith, \& Cacioppo, 1998). It appears, then, that threat may be a more potent motivator than is enhancement. Consequently, motivational primacy might be revealed more conclusively in the case of threat.

\section{Method}

\section{Literature Searches}

We conducted computer searches on PsycINFO and the Social Sciences Citation Index. On PsycINFO, we searched from January 1970 to April 2000 using three specific search terms for the individual self (i.e., individual self, individual identity, personal identity) and three for the collective self (i.e., collective self, collective identity, social identity). Furthermore, we repeated the above search using two broader terms (i.e., individual and group) to prevent the possibility of excluding studies that satisfied our inclusion criteria but were not captured by the more focused search terms. On the Social Sciences Citation Index, we searched for articles citing authors who had published research relevant to the primacy issue, as we judged by the results of the PsycINFO search. Additionally, we browsed the social and personality psychology journals between January 1970 and April 2000. Finally, a helpful colleague brought to our attention a relevant unpublished experiment (Graetz, 1992). These searches produced 18 experiments and 37 effect sizes that fit the criteria for inclusion in the meta-analysis.

\section{Inclusion Criteria}

In an effort to assess the issue of motivational primacy as precisely as possible, we included in the meta-analysis primary studies that satisfied certain criteria regarding the independent and dependent variables. The independent variable ought to threaten separately the individual and collective self or enhance separately the individual and collective self. We excluded studies that explicitly and simultaneously directed feedback (either threatening or enhancing) to both selves (Barr \& Conlon, 1994; Chen, Brockner, \& Katz, 1998; Cialdini et al., 1976; Kawakami \& Dion, 1993; McFarland \& Buehler, 1995; Seta \& Seta, 1996; H. J. Smith \& Spears, 1996; Tindale, Kulik, \& Scott, 1991). Such studies prevent an assessment of whether the ensuing reaction was in response to the threatened (or enhanced) individual or collective self and, consequently, preclude the calculation of an effect size. Furthermore, primary studies ought to threaten (or enhance) the individual and collective self on comparable dimensions. We excluded studies that threatened or enhanced the individual and collective self on disparate dimensions (Hirt, Zillman, Erickson, \& Kennedy, 1992; H. J. Smith, Spears, \& Oyen, 1994), because such studies confounded target of feedback (individual vs. collective self) with dimension of feedback.

Examples of research included in the threat domain are studies that (a) provided unfavorable feedback about task performance or attributes pertaining to the individual and collective self, respectively, or (b) used a repeated measures design requiring participants to evaluate the individual and collective self, respectively, on unfavorable attributes. At issue was whether participants reacted more strongly (i.e., negatively) when one self was threatened than they did when the other self was threatened and whether participants were more or less likely to disassociate negative information from one self than from the other. Examples of research included in the enhancement domain are studies that (a) provided favorable feedback about the performance or attributes of the individual and collective self, respectively, or (b) used a repeated measures design requiring participants to evaluate the individual and collective self, respectively, on favorable dimensions. At issue was whether participants reacted more strongly (i.e., positively) when one self versus the other was enhanced and whether participants were more versus less likely to associate positive information with one self than with the other.

In regard to the inclusion criteria for the dependent variable, primary studies ought to report comparable responses associated with the individual and collective self. Relevant dependent variables assessed responses such as mood states, perceived positivity or negativity of feedback, and trait ratings of the individual and collective self. We excluded studies in which the dependent variable could not distinguish unambiguously which self was primary (Ellemers, van Knippenberg, de Vries, \& Wilke, 1988; Ellemers, van Knippenberg, \& Wilke, 1990; D. M. Taylor, Wright, Moghaddam, \& Lalonde, 1990). ${ }^{1}$

\section{Calculation of Effect Sizes}

We defined the effect size as the standardized mean difference between responses of the individual and collective selves to threat or enhancement. A positive effect size indicates that the individual self reacted more

\footnotetext{
${ }^{1}$ Research on the personal-group discrimination discrepancy (PGDD) indicates that participants report that they personally experience less discrimination than does their social group (e.g., D. M. Taylor et al., 1990). We excluded from the meta-analysis research on the PGDD, because explanations of the PGDD are mixed and do not determine clearly which self is motivationally primary. Motivational accounts suggest that the discrepancy arises from a self-protective strategy of denying personal discrimination (Crosby, 1984) or, on the other hand, a tendency to exaggerate levels of group discrimination (D. M. Taylor et al., 1990). Information processing accounts deny motivational origins of the discrepancy and offer as explanations a greater availability of episodes of group discrimination than personal discrimination (Moghaddam, Stolkin, \& Hutcheson, 1997) and different comparison standards that are elicited by judgments of personal discrimination than judgments of group discrimination (Kessler, Mummendey, \& Leisse, 2000). In any event, reports of whether or how much discrimination has been experienced differ from reports of how persons react to instances of personal versus group discrimination, with the latter being the direct focus of this meta-analysis.
} 
strongly than the collective self or more strongly associated positive traits with or disassociated negative traits from the individual than the collective self. Thus, positive effect sizes support the individual-self-primacy hypothesis. A negative effect size indicates that the collective self reacted more strongly than the individual self or more strongly associated positive traits with or disassociated negative traits from the collective than the individual self. Thus, negative effect sizes support the collective-self-primacy hypothesis. An effect size of zero indicates no difference between the reactions of the two selves or the extent of associating positive traits with and dissociating negative traits from the two selves. Finally, effect sizes with valences that depend on identification or group type support the contextualprimacy hypothesis.
We standardized the mean differences using the pooled sample standard deviation (i.e., we calculated Hedges's $g$; Hedges \& Olkin, 1985). To avoid inflating effect sizes from repeated measures designs, we pooled the standard deviations from each sample (i.e., individual self and collective self) as though the data had arisen from a between-groups design rather than using the error mean square that was appropriate for inference in the repeated measures analysis of variance. (Because repeated measures designs typically yield smaller error terms, failing to handle the effect-size calculation in this manner often results in a systematic tendency for repeated measures effect sizes to be larger.) Table 1 contains the studies included in the metaanalysis and their corresponding moderators, effect sizes, and conditional variances. Table 2 displays the characteristics of the included studies in regard to the independent variable, dependent variable, and collective self.

Table 1

Studies Included in the Meta-Analysis

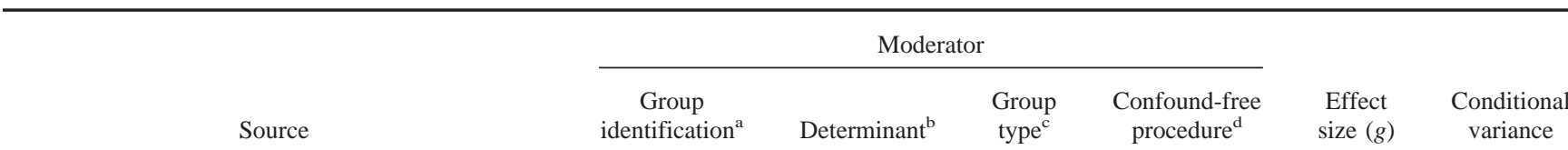

Biernat, Vescio, \& Green (1996, Experiment 1)

Biernat, Vescio, \& Green (1996, Experiment 2)

Biernat, Vescio, \& Green (1996, Experiment 3)

Cadinu \& Rothbart (1996, Experiment 1)

Cadinu \& Rothbart (1996, Experiment 2)

Cadinu \& Rothbart (1996, Experiment 3)

Duck, Hogg, \& Terry (1995)

Duck, Hogg, \& Terry (1995)

Gaertner, Sedikides, \& Graetz (1999, Experiment 1)

Gaertner, Sedikides, \& Graetz (1999, Experiment 2)

Gaertner, Sedikides, \& Graetz (1999, Experiment 2)

Gaertner, Sedikides, \& Graetz (1999, Experiment 3)

Graetz (1992, Experiment 2)

Jaffe \& Yinon (1979)

Lindeman (1997, Experiment 2)

Lindeman (1997, Experiment 2)

Threat domain

$\begin{array}{llllrl}\mathrm{H} & \mathrm{C} & \mathrm{N} & \mathrm{N} & -0.2402 & 0.0071 \\ \mathrm{H} & \mathrm{C} & \mathrm{N} & \mathrm{N} & 0.8374 & 0.0419 \\ \mathrm{H} & \mathrm{C} & \mathrm{N} & \mathrm{N} & 0.2782 & 0.0481 \\ \mathrm{H} & \mathrm{C} & \mathrm{M} & \mathrm{N} & 0.7797 & 0.0654 \\ \mathrm{H} & \mathrm{C} & \mathrm{M} & \mathrm{N} & 0.9498 & 0.0572 \\ \mathrm{H} & \mathrm{C} & \mathrm{M} & \mathrm{N} & 0.5097 & 0.0249 \\ \mathrm{H} & \mathrm{P} & \mathrm{N} & \mathrm{N} & 1.4565 & 0.0945 \\ \mathrm{~L} & \mathrm{P} & \mathrm{N} & \mathrm{N} & 0.8239 & 0.0837 \\ \mathrm{~L} & \mathrm{C} & \mathrm{N} & \mathrm{Y} & 1.0665 & 0.0717 \\ \mathrm{~L} & \mathrm{P} & \mathrm{N} & \mathrm{Y} & 0.3936 & 0.0342 \\ \mathrm{H} & \mathrm{P} & \mathrm{N} & \mathrm{Y} & 0.2320 & 0.0449 \\ \mathrm{H} & \mathrm{C} & \mathrm{M} & \mathrm{N} & 0.9126 & 0.1076 \\ \mathrm{H} & \mathrm{C} & \mathrm{N} & \mathrm{N} & 0.4187 & 0.0238 \\ \mathrm{H} & \mathrm{C} & \mathrm{M} & \mathrm{N} & -0.3323 & 0.1348 \\ \mathrm{H} & \mathrm{C} & \mathrm{N} & \mathrm{N} & 1.3015 & 0.2052 \\ \mathrm{H} & \mathrm{C} & \mathrm{N} & \mathrm{N} & 0.0995 & 0.0127\end{array}$

Enhancement domain

Biernat, Vescio, \& Green (1996, Experiment 1) Biernat, Vescio, \& Green (1996, Experiment 2) Biernat, Vescio, \& Green (1996, Experiment 3) Cadinu \& Rothbart (1996, Experiment 1) Cadinu \& Rothbart (1996, Experiment 2)

Cadinu \& Rothbart (1996, Experiment 3) Gaertner, Sedikides, \& Graetz (1999, Experiment 1)

Lindeman (1997, Experiment 1, Voters A)

Lindeman (1997, Experiment 1, Voters A)

Lindeman (1997, Experiment 1, Voters B)

Lindeman (1997, Experiment 1, Voters B)

Lindeman (1997, Experiment 2)

Lindeman (1997, Experiment 2)

Lindeman (1997, Experiment 2)

Lindeman (1997, Experiment 2)

Lindeman \& Sundvik (1995)

Lindeman \& Sundvik (1995)

Long \& Spears (1998)

Long \& Spears (1998)

Long \& Spears (1998)

Long \& Spears (1998)

\begin{tabular}{|c|c|c|c|c|c|}
\hline $\mathrm{H}$ & $\mathrm{C}$ & $\mathrm{N}$ & $\mathrm{N}$ & -0.0278 & 0.0070 \\
\hline $\mathrm{H}$ & $\mathrm{C}$ & $\mathrm{N}$ & $\mathrm{N}$ & 0.8569 & 0.0421 \\
\hline $\mathrm{H}$ & $\mathrm{C}$ & $\mathrm{N}$ & $\mathrm{N}$ & 0.9134 & 0.0527 \\
\hline $\mathrm{H}$ & $\mathrm{C}$ & M & $\mathrm{N}$ & 0.0635 & 0.0606 \\
\hline $\mathrm{H}$ & $\mathrm{C}$ & M & $\mathrm{N}$ & 0.4285 & 0.0525 \\
\hline $\mathrm{H}$ & $\mathrm{C}$ & M & $\mathrm{N}$ & 0.4129 & 0.0246 \\
\hline $\mathrm{L}$ & $\mathrm{C}$ & $\mathrm{N}$ & Y & 1.0032 & 0.0706 \\
\hline $\mathrm{L}$ & $\mathrm{P}$ & $\mathrm{N}$ & $\mathrm{N}$ & 0.3621 & 0.0384 \\
\hline $\mathrm{H}$ & $\mathrm{P}$ & $\mathrm{N}$ & $\mathrm{N}$ & 0.3621 & 0.0370 \\
\hline $\mathrm{L}$ & $\mathrm{P}$ & $\mathrm{N}$ & $\mathrm{N}$ & 1.0000 & 0.0525 \\
\hline $\mathrm{H}$ & $\mathrm{P}$ & $\mathrm{N}$ & $\mathrm{N}$ & 0.5714 & 0.0695 \\
\hline $\mathrm{H}$ & $\mathrm{P}$ & $\mathrm{N}$ & $\mathrm{N}$ & 1.3928 & 0.1480 \\
\hline $\mathrm{H}$ & $\mathrm{P}$ & $\mathrm{N}$ & $\mathrm{N}$ & -0.2661 & 0.0374 \\
\hline $\mathrm{L}$ & $\mathrm{P}$ & $\mathrm{N}$ & $\mathrm{N}$ & 0.6668 & 0.1413 \\
\hline $\mathrm{L}$ & $\mathrm{P}$ & $\mathrm{N}$ & $\mathrm{N}$ & 0.0000 & 0.0435 \\
\hline $\mathrm{H}$ & $\mathrm{C}$ & $\mathrm{N}$ & $\mathrm{N}$ & 0.5239 & 0.0314 \\
\hline $\mathrm{H}$ & $\mathrm{C}$ & $\mathrm{N}$ & $\mathrm{N}$ & 0.5430 & 0.0593 \\
\hline $\mathrm{H}$ & $\mathrm{C}$ & $\mathrm{N}$ & Y & -0.0996 & 0.1250 \\
\hline $\mathrm{H}$ & $\mathrm{C}$ & $\mathrm{N}$ & Y & 0.6352 & 0.1625 \\
\hline $\mathrm{H}$ & $\mathrm{C}$ & $\mathrm{N}$ & $\mathrm{Y}$ & -0.5362 & 0.1736 \\
\hline $\mathrm{H}$ & $\mathrm{C}$ & $\mathrm{N}$ & $\mathrm{Y}$ & -0.9173 & 0.1391 \\
\hline
\end{tabular}

${ }^{a}$ Group identification indicates whether participants were low identifiers (L) or high identifiers $(H)$.

${ }^{\mathrm{b}}$ Determinant indicates whether group identification was determined by the authors of the primary study $(\mathrm{P})$ or the authors of the current meta-analysis (C).

${ }^{\mathrm{c}}$ Group type indicates whether the collective self was a laboratory-created minimal group (M) or a preexisting natural group (N).

d Confound-free procedure indicates whether the procedure of the primary study directed feedback about the collective self exclusively to the collective self $(\mathrm{Y})$ or potentially directed feedback about the collective self to the collective self and the individual self $(\mathrm{N})$. 
Table 2

Characteristics of Studies Included in Meta-Analysis

\begin{tabular}{llll}
\hline \multicolumn{1}{c}{ Source } & \multicolumn{1}{c}{ Independent variable ${ }^{\mathrm{a}}$} & Dependent variable \\
\hline & \multicolumn{1}{c}{ Threat domain } & \\
& \multicolumn{1}{c}{ Collective self } \\
Biernat, Vescio, \& Green (1996, Experiment 1) & Repeated measure & Negative trait rating & Sorority affiliation \\
Biernat, Vescio, \& Green (1996, Experiment 2) & Repeated measure & Negative trait rating & University affiliation \\
Biernat, Vescio, \& Green (1996, Experiment 3) & Repeated measure & Negative trait rating & Fraternity affiliation \\
Cadinu \& Rothbart (1996, Experiment 1) & Repeated measure & Negative trait rating & Minimal group \\
Cadinu \& Rothbart (1996, Experiment 2) & Repeated measure & Negative trait rating & Minimal group \\
Cadinu \& Rothbart (1996, Experiment 3) & Repeated measure & Negative trait rating & Minimal group \\
Duck, Hogg, \& Terry (1995) & Repeated measure & Persuasion rating & Political affiliation \\
Duck, Hogg, \& Terry (1995) & Repeated measure & Persuasion rating & Political affiliation \\
Gaertner, Sedikides, \& Graetz (1999, Experiment 1) & Moody & Feedback valence & Gender \\
Gaertner, Sedikides, \& Graetz (1999, Experiment 2) & Lack creativity & Negative mood & University affiliation \\
Gaertner, Sedikides, \& Graetz (1999, Experiment 2) & Lack creativity & Negative mood & University affiliation \\
Gaertner, Sedikides, \& Graetz (1999, Experiment 3) & Insult from other & Anger & Minimal group \\
Graetz (1992, Experiment 2) & Recall threat to self or group & Anger & Gender \\
Jaffe \& Yinon (1979) & Insult & Anger & Minimal group \\
Lindeman (1997, Experiment 2) & Repeated measure & Negative trait rating & Gender \\
Lindeman (1997, Experiment 2) & Repeated measure & Negative trait rating & Gender \\
\hline
\end{tabular}

Enhancement domain

Biernat, Vescio, \& Green (1996, Experiment 1) Biernat, Vescio, \& Green (1996, Experiment 2)

Biernat, Vescio, \& Green (1996, Experiment 3)

Cadinu \& Rothbart (1996, Experiment 1)

Cadinu \& Rothbart (1996, Experiment 2)

Cadinu \& Rothbart (1996, Experiment 3)

Gaertner, Sedikides, \& Graetz (1999, Experiment 1)

Lindeman (1997, Experiment 1, Voters A)

Lindeman (1997, Experiment 1, Voters A)

Lindeman (1997, Experiment 1, Voters B)

Lindeman (1997, Experiment 1, Voters B)

Lindeman (1997, Experiment 2)

Lindeman (1997, Experiment 2)

Lindeman (1997, Experiment 2)

Lindeman (1997, Experiment 2)

Lindeman \& Sundvik (1995)

Lindeman \& Sundvik (1995)

Long \& Spears (1998)

Long \& Spears (1998)

Long \& Spears (1998)

Long \& Spears (1998)

Repeated measure
Repeated measure
Repeated measure
Repeated measure
Repeated measure
Repeated measure
Emotionally expressive
Repeated measure
Repeated measure
Repeated measure
Repeated measure
Repeated measure
Repeated measure
Repeated measure
Repeated measure
Repeated measure
Repeated measure
Repeated measure
Repeated measure
Repeated measure
Repeated measure

Repeated measure Repeated measure Repeated measure Repeated measure Repeated measure Emotionally expressive Repeated measure Repeated measure Repeated measure Repeated measure peated measure Repeated measure Repeated measure
Positive trait rating Positive trait rating Positive trait rating Positive trait rating Positive trait rating Positive trait rating Feedback valence

Bipolar trait rating Bipolar trait rating Bipolar trait rating Bipolar trait rating Positive trait rating Positive trait rating

Positive trait rating

Positive trait rating

Positive trait rating

Positive trait rating

Product evaluation

Product evaluation

Product evaluation Product evaluation
Sorority affiliation University affiliation Fraternity affiliation Minimal group Minimal group Minimal group Gender Political affiliation Political affiliation Political affiliation Political affiliation Gender Gender

Gender

Gender

Gender

Gender

Career

Career

Career Career

${ }^{a}$ Repeated measure indicates that participants rated the individual self and the collective self as part of a within-subject factor.

\section{Mixed-Effects Linear Model}

In approaching a meta-analytic synthesis, we needed to be clear about the type of inference that we wanted to draw. One class of statistical models (the fixed-effects model) is appropriate when the inferential goal is to consider randomness associated with the sampling of participants into experiments and treatment conditions for a particular set of experiments. A different class of models (the random-effects model) is appropriate when a researcher wishes, in addition, to consider the experiments that one analyzes as a sample from a universe of possible experiments. That is, the random-effects model is appropriate if a researcher wishes to generalize results beyond exact replications of the particular experiments that are available. The random-effects model differs conceptually from the fixedeffects model in that, rather than estimating a single common population effect, it estimates the mean of a population of possible effects, where the true population effects that individual experiments estimate may differ from experiment to experiment. That additional source of variation is usually accounted for by the estimation of a variance component that represents between-experiments variability of population effects. In addition, it is possible to develop explanatory models for such variation. When such explanatory models are applied in the context of a random-effects model, the resulting model is called a mixed-effects model.

In the present meta-analysis, our interest was in inference that generalizes to a universe of possible experiments of the self-definitional primacy issue. Hence, we used random-effects procedures. This is in keeping with the recommendations of the National Research Council (1992; see also Hedges \& Vevea, 1998, for further discussion of how the choice of statistical models relates to the type of inference desired). As we mentioned above, we were interested in possible associations between effect size and explanatory factors. Accordingly, we considered a series of mixed-effects models, described below. Random-effects models require an assumption of a normal distribution of effects from which the meta-analytic data set is a sample. Graphical exploration of standardized effects and residuals supported that assumption.

Because random-effects or mixed-effects models typically have lower power than their fixed-effects counterparts, we also considered a parallel series of fixed-effects models. The purpose of examining these fixedeffects models was to provide evidence that our possibly controversial choice of analytic approach did not lead us to radically different conclu- 
sions than a more traditional analysis would have provided. Historically, the most common approach to meta-analysis has been to begin with a fixed-effects model and attempt to explain variation in effect sizes with moderators. After the addition of such moderating variables, the effect sizes might still be more variable than one would expect if they were estimates of a single, common population effect. In such cases, a variance component is added to describe the excess variability, resulting in the same mixed-effects model that we have advocated on theoretical grounds. The test for excess variability is the same $Q$ statistic that, in the random-effects or mixed-effects context, tests the null hypothesis that the variance component is zero. The addition of the variance component is necessary because without it the standard errors of the fixed-effects model understate the true uncertainty of estimation. Hence, inference in heterogeneous (misspecified) fixed-effects models is severely flawed: Type I errors occur much more frequently than indicated by the nominal alpha level, and confidence intervals for population effects are artificially narrow.

We estimated the parameters of the mixed-effects and random-effects models by unconditional maximum likelihood, using a specialized computer program developed for that purpose (Vevea \& Hedges, 1995). We estimated fixed-effects models by weighted least squares, which is also a maximum likelihood procedure in this context. We estimated a parallel series of models for the threat domain and for the enhancement domain. We conducted tests of the significance of model components using largesample $Z$ tests for each of the model parameters, which we calculated by dividing parameter estimates by their respective standard errors. We assessed these tests using the standard normal distribution. Within each domain, the sequence of models addressed the following questions:

1. Need we be concerned with the potential procedural confound in which select studies may have directed collective-self threats (enhancements) additionally to the individual self?

2. Does group identification matter, and does it matter whether the primary authors or the present authors determined identification?

3. Does group type (minimal vs. natural) matter?

For models containing identification or group type, tests of the null hypothesis that the identification effect or group type effect is equal to zero represent tests of the contextual-primacy hypothesis. Keeping in mind concerns about null confirmation and lack of power, if we fail to reject these null hypotheses, the implication is that a simple random-effects model may be more appropriate (i.e., one in which a single mean population effect is estimated, with the variability of population effects described by a variance component). In the context of that model, the valence of the effect distinguishes the individual-self-primacy hypothesis (positive sign) and the collective-self-primacy hypothesis (negative sign). And a comparison of the effect against zero provides a significance test of the finding. If we determine that the simple model is inadequate, then the valence of the predicted conditional means for different cells of the more complex models carry the same meaning.

\section{Results}

Most experiments pertaining to the issue of self-definitional primacy included threatening and enhancing situations as a repeated measures factor. To avoid complications involving lack of statistical independence and missing data, we considered the two types of situations separately.

\section{Threat Domain}

Table 3 contains the parameter estimates of the statistical models from the threat domain, with estimates from the mixed-effects analyses presented on the left side of the table and estimates from the fixed-effects analyses presented on the right side of the table. Before reviewing the results, we should note that the mixed-effects analysis of each model revealed significant variability in excess of what could be accounted for by the moderators. Consequently, the fixed-effects models, which do not model the excess variability, are misspecified and excessively underestimate standard errors. The consequence of such underestimation is that the inferential tests provided by fixed-effects models are inaccurate (i.e., too liberal). Field (2001), for example, reported that fixed-effects models result in Type I error rates ranging from $31 \%$ to $72 \%$ when between-studies variability is excessive.

Some studies in the analysis purporting to direct threat exclusively to the collective self were successful in doing so, whereas

Table 3

Parameter Estimates for the Threat Domain

\begin{tabular}{|c|c|c|c|c|c|c|c|c|}
\hline \multirow[b]{2}{*}{ Parameter } & \multicolumn{4}{|c|}{ Mixed-effects analysis } & \multicolumn{4}{|c|}{ Fixed-effects analysis } \\
\hline & Estimate & $S E$ & $Z$ & $p>|Z|$ & Estimate & $S E$ & $Z$ & $p>|Z|$ \\
\hline \multicolumn{9}{|l|}{$\begin{array}{l}\text { Model involving counfound-free } \\
\text { procedure }^{\mathrm{a}}\end{array}$} \\
\hline Intercept & 0.545 & 0.148 & 3.682 & .000 & 0.364 & 0.066 & 5.515 & .000 \\
\hline Confound free & -0.003 & 0.148 & -0.020 & .984 & 0.118 & 0.066 & 1.787 & .074 \\
\hline \multicolumn{9}{|l|}{$\begin{array}{l}\text { Model involving identification } \\
\text { and determinant }\end{array}$} \\
\hline Intercept & 0.717 & 0.162 & 4.426 & .000 & 0.602 & 0.090 & 6.689 & .000 \\
\hline Identification & -0.107 & 0.162 & 0.660 & .509 & -0.191 & 0.090 & 2.122 & .034 \\
\hline Determinant & 0.041 & 0.162 & 0.253 & .800 & 0.030 & 0.090 & 0.333 & .739 \\
\hline Identification $\times$ Determinant & -0.202 & 0.162 & -1.247 & .212 & -0.245 & 0.090 & -2.722 & .006 \\
\hline \multicolumn{9}{|l|}{ Model involving group type $\mathrm{d}^{\mathrm{d}}$} \\
\hline Intercept & 0.560 & 0.128 & 4.375 & .000 & 0.408 & 0.058 & 7.034 & .000 \\
\hline Group type & -0.036 & 0.128 & -0.281 & .779 & -0.206 & 0.058 & -3.552 & .000 \\
\hline \multicolumn{9}{|l|}{$\begin{array}{l}\text { Simple model (intercept only or } \\
\text { average effect size) }\end{array}$} \\
\hline Intercept & 0.546 & 0.119 & 4.588 & .000 & 0.277 & 0.045 & 6.156 & .000 \\
\hline
\end{tabular}

Note. All $p$ values are two-tailed.

${ }^{\mathrm{a}}$ Confound free $(-1=$ no and $1=$ yes $) . \quad{ }^{\mathrm{b}}$ Identification $(-1=$ low and $1=$ high $) . \quad{ }^{\mathrm{c}}$ Determinant $(-1=$ authors of primary study and $1=$ authors of current meta-analysis). ${ }^{\mathrm{d}}$ Group type $(-1=$ minimal group and $1=$ natural group) 
other studies purporting to threaten the collective self may have additionally threatened the individual self. The first part of Table 3 presents estimates for the model that distinguished between those two paradigms. (The confound variable is coded 1 or -1 , depending on whether threat to the collective self was unambiguously directed to the collective self or not.) The inferential tests of the fixed effects should be disregarded, as indicated by the significant variance component of the mixed-effects model (variance component $=0.163), Q(14)=98.335, p<.001$. Both the mixed-effects analysis and the fixed-effects analysis estimated the effect of the potential confound to be small in magnitude, and the mixed-effects analysis indicated that it was nonsignificant.

The second part of Table 3 presents the estimates for the model that tests whether reaction to threat of the individual versus the collective self was moderated by group identification (coded -1 for low and 1 for high), determinant (i.e., who determined level of identification; coded -1 for authors of the primary study and 1 for authors of the current meta-analysis), or an interaction between those factors. Again, the fixed-effects model is misspecified, as indicated by the significant variance component of the mixedeffects analysis (variance component $=0.134$ ), $Q(12)=83.795$, $p<.001$. The mixed-effects and fixed-effects analyses produced similar parameter estimates, and the inferential tests of the mixedeffects analysis indicated that the effects of identification, determinant, and Identification $\times$ Determinant were nonsignificant. Contrary to the contextual-primacy hypothesis, group identification does not moderate relative reactions to threat of the individual versus the collective self.

On the other hand, a skeptic might argue that a different conclusion is indicated by the inferential tests of the fixed-effects analysis. In particular, the fixed-effects analysis suggests that the Identification $\times$ Determinant effect is statistically significant. Such a skeptic should keep in mind, however, that the $p$ values from the fixed-effects model are inaccurately low because the fixed-effects model is misspecified and the standard errors are underestimated. In any event, the apparent discrepancy between the analysis strategies can be resolved, in part, by an examination of the predicted mean effect size for each cell of the interaction. The predicted means from the mixed-effects and random-effects models are displayed in the top part of Table 4 (again, the $p$ values for the fixed-effects analysis cannot be taken at face value). All of the predicted means (from both analysis strategies) are positively valenced and indicate that low and high group identifiers react more strongly to a threat to the individual than to the collective self. Such a pattern is consistent with the individual-self-primacy hypothesis.

The third part of Table 3 presents the estimates for the model that tests whether reaction to threat of the individual versus the collective self was moderated by the type of group on which the collective self was based $(-1=$ minimal group, $1=$ natural group). Once again, inferences based on the $p$ values of the fixed-effects analysis are compromised, as suggested by the significant variance component of the mixed-effects analysis (variance component $=0.159), Q(14)=89.080, p<.001$. Contrary to the contextual-primacy hypothesis, the mixed-effects analysis clearly indicates that group type is not a significant moderator. On the other hand, if we (incorrectly) disregarded the fact that the fixed-effects model is misspecified, we would conclude that group type is a significant moderator, such that the tendency toward individual-self primacy is stronger when the collective self is derived from a minimal group. Again, this apparent discrepancy can be resolved by an examination of the predicted means for minimal groups and natural groups. Those predicted means are in the bottom part of Table 4 . For both minimal groups and natural groups, the predicted means (from both the mixed-effects and the fixed-effects analysis) are positively valenced. Consistent with the individual-self-primacy hypothesis, people react more strongly to a threat to the individual than the collective self, regardless of whether the collective self is derived from a minimal or a natural group.

The fourth part of Table 3 presents the estimates from a simple model that estimates the average population effect size, averaging across the previously examined moderators. As in the previous analyses, inferences based on the fixed-effects analysis are questionable, as indicated by the significant variance component of the mixed-effects analysis (variance component $=0.163$ ), $Q(15)=$ 101.502, $p<.001$. As would be expected on the basis of the predicted means from the previously examined models, the average population effect size is positively valenced (for both the mixed-effects and the fixed-effects analyses) and indicates that people react more strongly to threat to the individual than to the collective self. Such a finding is consistent with the individualself-primacy hypothesis.

\section{Enhancement Domain}

Table 5 contains the parameter estimates of the statistical models from the enhancement domain, with estimates from the mixed-

Table 4

Predicted Values for the Threat Domain

\begin{tabular}{|c|c|c|c|c|c|c|c|c|c|}
\hline \multirow[b]{2}{*}{ Condition } & \multirow{2}{*}{$\begin{array}{l}\text { No. of } \\
\text { effects }\end{array}$} & \multicolumn{4}{|c|}{ Mixed-effects analysis } & \multicolumn{4}{|c|}{ Fixed-effects analysis } \\
\hline & & Prediction & $S E$ & $Z$ & $p>|Z|$ & Prediction & $S E$ & $Z$ & $p>|Z|$ \\
\hline \multicolumn{10}{|l|}{ Model involving identification and determinant } \\
\hline High identification, as determined by primary authors & 2 & 0.770 & 0.317 & 2.430 & .015 & 0.626 & 0.174 & 3.598 & .000 \\
\hline Low identification, as determined by primary authors & 2 & 0.581 & 0.308 & 1.886 & .059 & 0.518 & 0.156 & 3.321 & .000 \\
\hline High identification, as determined by current authors & 11 & 0.449 & 0.130 & 3.454 & .001 & 0.196 & 0.050 & 3.920 & .000 \\
\hline Low identification, as determined by current authors & 1 & 1.067 & 0.453 & 2.355 & .019 & 1.067 & 0.268 & 3.981 & .000 \\
\hline \multicolumn{10}{|l|}{ Model involving group type } \\
\hline Minimal group & 5 & 0.597 & 0.215 & 2.777 & .005 & 0.614 & 0.106 & 5.792 & .000 \\
\hline Natural group & 11 & 0.524 & 0.138 & 3.797 & .000 & 0.202 & 0.050 & 4.040 & .000 \\
\hline
\end{tabular}

Note. All $p$ values are two-tailed. 
Table 5

Parameter Estimates for the Enhancement Domain

\begin{tabular}{|c|c|c|c|c|c|c|c|c|}
\hline \multirow[b]{2}{*}{ Parameter } & \multicolumn{4}{|c|}{ Mixed-effects analysis } & \multicolumn{4}{|c|}{ Fixed-effects analysis } \\
\hline & Estimate & $S E$ & $Z$ & $p>|Z|$ & Estimate & $S E$ & $Z$ & $p>|Z|$ \\
\hline \multicolumn{9}{|c|}{ Model involving confound-free procedure ${ }^{a}$} \\
\hline Intercept & 0.265 & 0.132 & 2.008 & 045 & 0.244 & 0.081 & 3.012 & .003 \\
\hline Confound free & -0.188 & 0.132 & -1.424 & .154 & -0.058 & 0.081 & -0.716 & .474 \\
\hline \multicolumn{9}{|c|}{ Model involving identification ${ }^{\mathrm{b}}$ and determinant $\mathrm{c}^{\mathrm{c}}$} \\
\hline Intercept & 0.548 & 0.143 & 3.832 & .000 & 0.487 & 0.079 & 6.165 & .000 \\
\hline Identification & -0.196 & 0.143 & 1.371 & .170 & -0.235 & 0.079 & -2.975 & .003 \\
\hline Determinant & 0.098 & 0.143 & 0.685 & .493 & 0.131 & 0.079 & 1.658 & .097 \\
\hline Identification $\times$ Determinant & -0.161 & 0.143 & -1.126 & .260 & -0.150 & 0.079 & -1.899 & .058 \\
\hline \multicolumn{9}{|l|}{ Model involving group type ${ }^{\mathrm{d}}$} \\
\hline Intercept & 0.353 & 0.142 & 2.486 & .013 & 0.312 & 0.062 & 5.032 & .000 \\
\hline Group type & 0.043 & 0.142 & 0.303 & .762 & -0.029 & 0.062 & -0.467 & .640 \\
\hline \multicolumn{9}{|c|}{ Simple model (intercept only or average effect size) } \\
\hline Intercept & 0.383 & 0.161 & 2.379 & .017 & 0.292 & 0.045 & 6.489 & .000 \\
\hline
\end{tabular}

Note. All $p$ values are two-tailed.

${ }^{\mathrm{a}}$ Confound free $(-1=$ no and $1=$ yes $) . \quad{ }^{\mathrm{b}}$ Identification $(-1=$ low and $1=$ high $) . \quad{ }^{\mathrm{c}}$ Determinant $(-1=$ authors of primary study and $1=$ authors of current meta-analysis). ${ }^{\mathrm{d}}$ Group type $(-1=$ minimal group and $1=$ natural group).

effects analyses presented on the left side of the table and estimates from the fixed-effects analyses presented on the right side of the table. As in the previous analyses, the mixed-effects analysis of each model revealed significant variability in excess of what could be accounted for by the moderators. Consequently, the fixedeffects models are misspecified, and the $p$ values should be disregarded.

The first part of the table presents estimates for the model that tests whether the effect sizes were moderated by whether primary studies used a procedure that unambiguously unconfounded enhancement of the collective self from the individual self. Although the fixed-effects model is misspecified, as indicated by the significant variance component of the mixed-effects analysis (variance component $=0.151), Q(19)=87.569, p<.001$, both models point to the same conclusion regarding the potential procedural confound. The effect of the procedural factor is nonsignificant, which indicates that we need not be concerned with this procedural factor when testing the competing hypotheses in the enhancement domain.

The second part of Table 5 presents the estimates for the model that tests whether reaction to enhancement of the individual versus collective self was moderated by group identification and deter- minant. Again, the inferential tests of the fixed-effects estimates are compromised, as indicated by the significant variance component of the mixed-effects analysis (variance component $=0.138$ ), $Q(17)=78.066, p<.001$. The fixed-effects and mixed-effects analyses again produced similar parameter estimates and, inconsistent with the contextual-primacy hypothesis, the inferential tests of the mixed-effects analysis indicated that group identification is not a significant moderator. Skeptics who wish to disregard the inferential problems with the fixed-effects model should examine the predicted means for the mixed-effects and fixed-effect models, which are presented in the top part of Table 6. Consistent with the individual-self-primacy hypothesis, all of the mean effect sizes are positively valenced and suggest that low and high group identifiers react more strongly to enhancement of the individual than the collective self. Again, such a pattern is consistent with the individual-self-primacy hypothesis.

The third part of Table 5 presents the estimates for the model that tests whether reaction to enhancement of the individual versus the collective self varied as a function of whether the collective self was derived from a minimal or a natural group. Although the fixed-effects model is misspecified, as indicated by the significant variance component of the mixed-effects analysis (variance com-

Table 6

Predicted Values for the Enhancement Domain

\begin{tabular}{|c|c|c|c|c|c|c|c|c|c|}
\hline \multirow[b]{2}{*}{ Condition } & \multirow{2}{*}{$\begin{array}{l}\text { No. of } \\
\text { effects }\end{array}$} & \multicolumn{4}{|c|}{ Mixed-effects analysis } & \multicolumn{4}{|c|}{ Fixed-effects analysis } \\
\hline & & Prediction & $S E$ & $Z$ & $p>|Z|$ & Prediction & $S E$ & $Z$ & $p>|Z|$ \\
\hline \multicolumn{10}{|l|}{ Model involving identification and determinant } \\
\hline High identification, as determined by primary authors & 4 & 0.414 & 0.225 & 1.840 & .066 & 0.271 & 0.116 & 2.336 & .019 \\
\hline Low identification, as determined by primary authors & 4 & 0.484 & 0.224 & 2.161 & .031 & 0.442 & 0.115 & 3.843 & .000 \\
\hline High identification, as determined by current authors & 12 & 0.288 & 0.130 & 2.215 & .027 & 0.234 & 0.054 & 4.333 & .000 \\
\hline Low identification, as determined by current authors & 1 & 1.003 & 0.457 & 2.195 & .028 & 1.003 & 0.266 & 3.771 & .000 \\
\hline \multicolumn{10}{|l|}{ Model involving group type } \\
\hline Minimal group & 3 & 0.310 & 0.261 & 1.188 & .235 & 0.341 & 0.115 & 2.965 & .003 \\
\hline Natural group & 18 & 0.397 & 0.113 & 3.513 & .000 & 0.284 & 0.045 & 6.311 & .000 \\
\hline
\end{tabular}

Note. All $p$ values are two-tailed. 
ponent $=0.160), Q(19)=87.871, p<.001$, both models point to the same conclusion: Group type is not a significant moderator. To maintain consistency with the previous analyses, we should examine the predicted mean effect sizes for the minimal and natural groups. As displayed in the bottom part of Table 6, all of the predicted means are positively valenced and indicate that persons respond more strongly to enhancement of the individual self than the collective self. The one anomaly, however, is that the positively valenced effect for the minimal group vastly deviates from significance in the context of the mixed-effects analysis. The more critical effect, of course, is the mean for the natural group, which, according to the contextual-primacy hypothesis, should be negatively valenced and indicate stronger reactions to enhancement of the collective than the individual self. Such a pattern is clearly not present in that the effect is positively valenced and significantly different than zero. Why the corresponding effect for minimal groups does not differ from zero is puzzling. Nonetheless, both the mixed-effects and the fixed-effects models agree that effects sizes of the minimal and natural groups do not differ and should be combined to provide a more reliable estimate of the population effect.

The fourth part of Table 5 presents the estimates from a simple model that estimates the average population effect size averaging across the previously examined moderators. Again, the fixedeffects model is misspecified, as indicated by the significant variance component of the mixed-effects analysis (variance component $=0.162), Q(20)=88.805, p<.001$. Nonetheless, both models estimate a positive effect size and suggest that persons react more strongly to enhancement of the individual than the collective self. Again, this evidence is consistent with the individual-self-primacy hypothesis.

\section{Discussion}

The balance between the individual and the collective self has been debated for over two and a half millennia. Sophists offered the first cohesive philosophical treatise in defense of the individual self, a view challenged by Plato in his formulations of the ideal society. Cicero and other Roman lawyers echoed sophistic arguments (Huntington, 1993). The issue was also prevalent in 13th century Britain and in other European states in the later Middle Ages (Macfarlane, 1978) as well as in the East (i.e., China), particularly during the Ming dynasty (deBary, 1979). Nineteenth and 20th century philosophy, psychology, and sociology persistently carried this tradition (Blumer, 1969; Cooley, 1902; Durkheim, 1950; James, 1890/1983; Mead, 1934; Rogers, 1997; Weber, 1964). In the last 2 decades, there has been an explosion of theory and research in social and personality psychology on the interplay between the individual and collective self (Abrams \& Hogg, 1990, 1999; Sedikides \& Brewer, 2001; Tajfel, 1982; Triandis, 1995; Turner et al., 1987; Tyler, Kramer, \& John, 1999).

\section{Summary of Meta-Analytic Findings}

Naturally, a researcher is in awe of the voluminous literature and the countless shades that mark the complex and intricate debate on the individual self and the collective self. Researchers have the choice either to raise up their arms in exasperation (and tacitly admit that all theoretical approaches are equally correct) or to venture in a scholarly foray (however limited) into synthesis of available knowledge. We opted for the latter. In the process, we followed Platt's (1964) advice that "you must study the simplest system you think has the properties you are interested in" (p. 349). Thus, we attempted to isolate critical aspects of the debate in their simplest form and investigate them through a powerful tool. The aspect was motivational primacy in self-definition. The tool was a meta-analysis.

We tested three hypotheses. The individual-self-primacy hypothesis maintains that the individual self is the most fundamental basis of self-definition, as far as motivation is concerned. In contrast, the collective-self-primacy hypothesis suggests that the collective self is the most fundamental basis of self-definition. The contextual-primacy hypothesis states that neither self is inherently motivationally primary; primacy depends on contextual factors that affect the momentary accessibility of the two selves.

Although the empirical literature contained only one set of studies that was designed explicitly to test the issue of motivational primacy, we uncovered 37 effects relevant to the issue. We tested the competing hypotheses with a meta-analytic integration of the relevant effects. According to our general framework, the more primary self reacts more intensely to threatening and enhancing information and more readily associates with enhancing information and disassociates from threatening information than does the less primary self (K. W. Campbell \& Sedikides, 1999; Sedikides \& Gaertner, 2001a).

On the basis of our interest in generalizing the results of the meta-analysis beyond the characteristics specific to the studies included in the analysis, we used random-effects (or, when moderators were present, mixed-effects) procedures. To prevent biasing our conclusions by reliance on one class of statistical model, we concurrently used more traditional fixed-effects procedures. The two analytic strategies produced relatively similar parameter estimates across the various models that we tested. However, the analysis strategies produced, at times, discrepant results in regard to the inferential tests of the parameter estimates. The significant variance component estimated by the mixed-effects analyses indicated that the discrepant inferential conclusions were due, primarily, to the misspecified fixed-effects models.

Rather than simply defaulting to the results of the mixed-effects procedures, we took an additional step to assess the apparent discrepancies and examined the predicted effect sizes generated by each analysis strategy. This additional step proved fruitful. The effect sizes generated by the strategies were relatively similar in magnitude and valence. Furthermore, the valence was consistent with the individual-self-primacy hypothesis and inconsistent with the collective-self and contextual-primacy hypotheses. In particular, participants reacted more strongly to threats to and enhancement of the individual than the collective self. This pattern occurred for both low and high group identifiers and for collective selves that were derived from minimal and natural groups.

In the introduction, we reviewed literature suggesting that threat is a more potent motivator than is enhancement. On the basis of this literature, we anticipated that individual-self primacy would be manifested strongly in the case of threat but weakly (or not at all) in the case of enhancement. It is interesting that the results did not confirm our expectation. Individual-self primacy was displayed in equal force under threat and enhancement conditions, thus broadening the scope of our argument. 


\section{Limitations and Caveats}

Before extrapolating from the data and discussing implications of the individual-self-primacy perspective, we consider potential limitations of this meta-analysis. Such limitations involve (a) effect distribution, (b) alternative explanations, and (c) individualself moderators. Additionally, we offer a caveat referring to breadth of generalization.

\section{Effect Distribution}

Although we were able to identify 37 effects relevant to the issue of motivational primacy, a quick glance at Tables 4 and 6 reveals that those effects were not evenly distributed across levels of the moderators. This unbalanced distribution is not problematic for the estimation of cell means. However, the low frequency of effects in certain conditions should serve as a warning that this meta-analysis is not the final word on the issue and instead represents a synthesis of the available evidence.

It is noteworthy, however, that higher frequency of effects occurred in the conditions (i.e., levels of moderators) that had the greatest potential for accruing evidence inconsistent with the individual-self-primacy hypothesis. In particular, the collectiveself-primacy and contextual-primacy hypotheses both predict negatively valenced means (i.e., stronger reactions to threat or enhancement of the collective than the individual self) for high group identifiers and natural groups. Those latter conditions contained the highest frequency of effects and yielded positively valenced predicted means (i.e., stronger reaction to threat or enhancement of the individual self).

\section{Alternative Explanations}

We considered it vital to the meta-analytic conclusions to be able to equate the strength of threat (enhancement) when comparing reactions of the two selves. Thus, we did our best to control for a potential confound by including studies in the meta-analysis on the condition that they threatened (enhanced) the selves on comparable dimensions. Nevertheless, it is possible that threat (enhancement) was stronger when directed to one self than another. We discuss two variations of this criticism below.

Is the collective self more amenable to reconstruction and disidentification than the individual self? It is possible that the collective self is more flexible, that is, more amenable to accommodating reconstruction and disidentification. If so, this statement would qualify as an alternative explanation to the results.

However, there are serious reasons to doubt the validity of this rival hypothesis. Although there is evidence pointing to the capacity of the collective self for reconstruction (Cadinu \& Cerchioni, 2001; Lalonde, 1992), there is also evidence to the contrary (Ryen \& Kahn, 1975) and, additionally, evidence that is mixed (Jackson, Sullivan, Harnish, \& Hodge, 1996). In stark contrast, the evidence showcasing the capacity of the individual self for reconstruction is unequivocal (Baumeister \& Jones, 1978; Greenberg \& Pyszczynski, 1985; Steele, 1988; Tesser, 2000; Wicklund \& Gollwitzer, 1982). In a similar vein, there is no reason to believe that disidentification is easier at the level of the collective self. If anything, the available literature suggests that disidentification is more apt to be used as a coping mechanism at the level of the individual self (e.g., Gaertner et al., 1999, Experiment 1). Mussweiler, Gabriel, and
Bodenhausen (2000) and Crocker, Voelki, Testa, and Major (1991) demonstrated that disidentification is used as a protective strategy in the face of threat to the individual self. Likewise, the tendency to publicly associate with a winning in-group is significantly more likely, if not done exclusively, following a threat to the individual self (Cialdini et al., 1976, Experiment 2).

More generally, though, this rival hypothesis is applicable only to studies in which threat (enhancement) is operationalized through feedback directed to the two selves. This hypothesis does not apply to studies in which threat (enhancement) was operationalized by trait-rating tasks on which participants could associate or dissociate the selves from positive or negative traits.

Is the collective self more cognitively complex than the individual self? Some readers might take issue with the manner in which we operationalized threat and enhancement of the individual and collective self and argue that the findings are due to the differential cognitive complexity of the two selves. In particular, threat (enhancement) of the individual and collective self was operationalized, in part, with rating tasks in which participants rated the extent to which they consider negative (positive) traits to be descriptive of themselves as people and of their group. In other words, the individual self was seemingly assessed with ratings of a particular person (i.e., the participant), whereas the collective self was seemingly assessed with ratings of an entire group (i.e., a group to which the participant belongs). On the basis of Linville's (1982) complexity-extremity effect (i.e., social and nonsocial objects are evaluated less extremely to the extent to which they are cognitively represented more complexly), the results of the metaanalysis might be attributed to people having a more complex representation of the collective than the individual self.

There are reasons to believe, however, that people likely have a more differentiated cognitive representation of the individual rather than the collective self. More recent research by Linville and colleagues (Linville, Fischer, \& Salovey, 1989; Linville, Fischer, \& Yoon, 1996; see also Ostrom, Carpenter, Sedikides, \& Li, 1993) indicates that a complex cognitive representation of an object (i.e., person or group) develops, in part, from familiarity with the object. The more familiar a perceiver is with an object, the more detailed knowledge of the object the perceiver forms and, hence, the more elaborated and differentiated the knowledge structure is. The self is a social object with which people have the utmost familiarity (Prentice, 1990). Private feelings and goals are highly prevalent and accessible (Andersen, 1984; Andersen, Glassman, \& Gold, 1998). The individual self is so omnipresent that people at times expend astounding levels of energy in an attempt to escape it (Baumeister, 1991). Even more convincing than a theoretical argument for the greater complexity of the individual than collective self are empirical data. Although raw counts of attributes are a crude assessment of the complexity of a cognitive representation (Linville et al., 1989), self-description tasks reveal that people list more aspects of their individual than their collective self regardless of culture of origin (Trafimow et al., 1991), construal of self as an individualist versus collectivist (Gaertner et al., 1999, Experiment 4), and situational manipulations of the salience of the selves (Trafimow et al., 1991; Ybarra \& Trafimow, 1998, Experiment 3). In summary, theoretical and empirical evidence indicate that people have a more complex representation of themselves as individuals than of themselves as in-group members. In that case, the tendency for people to more strongly disassociate (associate) negative (positive) traits from (with) the individual than the collective 
self is that much more impressive and cannot be explained by a tendency to rate the group less extremely because of its greater complexity.

Regardless, we wish to add that this meta-analysis has gone a long way to control for structural complexity of the individual versus the collective self. In both cases, the unit of analysis is the person. It is only the emphasis that differs. In the case of the individual self, participants rate the self as a unique person, whereas in the case of the collective self, participants rate the self as a person who belongs to an in-group (e.g., Gaertner et al., 1999). Moreover, even if there was a structural discrepancy, it would not be clear at all how this discrepancy would be translated into motivational differences between the two selves. That is, we operationalized threat and enhancement more broadly than solely assessing extremity of self and group on trait ratings. We also assessed strength of response (e.g., anger, mood state) to positive and negative feedback-an operationalization to which the complexity explanation does not apply.

\section{Individual-Self Moderators}

We searched persistently for contextual variables or moderators. We did not, however, adopt the equivalent fervor for individualself variables or moderators. That is, we did not consider the variable strength of identification with the individual self. For example, persons who have high self-esteem (Blaine \& Crocker, 1993), have a clear self-concept (J. D. Campbell et al., 1996), are narcissistic (Sedikides, Campbell, Reeder, Elliot, \& Gregg, 2002), are ego resilient (Block, 1961), or have a hardy personality (Wiebe, 1991) react unusually strongly and protectively against threat to the individual self. These persons will rely disproportionately on the individual self for self-definition.

\section{Breadth of Generalizations}

The random-effects analysis enables us more confidently to generalize the findings of individual-self primacy beyond exact replications of the synthesized studies. Nonetheless, we acknowledge that there may be extenuating circumstances to which the findings do not generalize. In such extreme situations, the collective self might take precedence. Thus, it may be premature to rule out the contextual-primacy hypothesis in its entirety. Perhaps a more conservative interpretation of the findings is that typically or under most circumstances the motivational hierarchy of the selfconcept is skewed toward the primacy of the individual self.

Having addressed potential limitations, we can now more appropriately extrapolate beyond the data and develop the theoretical position of individual-self primacy. In the following sections, we (a) elucidate connections between the current findings and a broader literature, (b) further clarify the individual-self-primacy approach, and (c) consider implications of individual-self primacy.

\section{Connections}

The meta-analytic findings are consistent with several other lines of inquiry. The individual self occupies a privileged place in memory (Klein, 2001). This self also provides the fodder and impetus for behavioral regulation, with groups and the social context serving as the background within which the person acts (Carver \& Scheier, 1998; Higgins, 1996; Higgins \& May, 2001) and carries out important goals and roles, interchangeably termed "personal strivings" (Emmons, 1986), "personal projects" (Little, 1983), "life tasks" (Cantor, Markus, Niedenthal, \& Nurius, 1986), and "possible selves" (Markus \& Nurius, 1986).

Furthermore, aspects of the individual-self permeate social relations. Self-schemata organize and guide the processing of information about others (Dunning, 1999; Green \& Sedikides, 2001), and they are readily and frequently projected on others (Kenny \& DePaulo, 1993; Krueger, 2000). Indeed, the individual self is used as the epistemic platform for the formation of knowledge about the collective self: Participants rely on individual-self knowledge to form an impression of the in-group in minimal-group situations (Gramzow, Gaertner, \& Sedikides, 2001; Otten \& Wentura, 2001). Self-determination theory emphasizes individual strivings for autonomy and competence and gives secondary importance to the role of social context (Deci \& Ryan, 2000). So strong is the need for uniqueness that people accentuate intragroup differences to a greater degree than intragroup similarities (Simon, Pantaleo, \& Mummendey, 1995). Additionally, the self-aspect model of the individual and collective self proposes that those aspects of the individual self that are positive and important form the basis for the collective self (Simon \& Hastedt, 1999; Simon \& Kampmeier, 2001). Arguably, a reason for the high self-definitional relevance of the individual self is the availability, accessibility, and inescapability of private feelings and goals (Andersen, 1984; Andersen et al., 1998; Andersen, Lazowski, \& Donisi, 1986). It is no surprise, then, that a strong individual self is associated with psychological health benefits (Gramzow, Sedikides, Panter, \& Insko, 2000).

\section{Clarifications}

In light of the meta-analytic findings, we feel the need to clarify further the position of individual-self primacy. We do not wish to cast the individual-self-primacy hypothesis as a restatement of self-interest theory, an interpretation to which the opening quote by Hobbes is amenable. Motivational primacy of the individual self is markedly different from material self-interest, a notion derived from the homo economicus model of human behavior (Miller, 1999). Also, we do not equate the motivational primacy of the individual self with selfishness, arrogance, and disregard for other persons, nor do we imply that such behaviors are unavoidable, justified, or acceptable. We refrain from valorizing the individual self, as this self has the potential to instigate both commendable and questionable behaviors (as does the collective self; e.g., intergroup cooperation and conflict).

More important, we wholeheartedly endorse the notion that the individual self is social. The individual self is in a dialectic relation with the collective self (Simon, 1997). This interactive relation is often harmonious, some times antagonistic, and other times context dependent (Deaux \& Perkins, 2001; Reid \& Deaux, 1996; Simon \& Kampmeier, 2001; Spears, 2001; Triandis \& Trafimow, 2001). Indeed, both selves are important in the regulation of social behavior. However, when the motivational potencies of the two selves are directly compared, one against the other, the individual self is shown to be more fundamental or primary.

\section{Implications}

Below, we consider broader implications of the meta-analytic findings for theory development in social and personality psychology. 


\section{Individual Self and Collective Self}

As stated above, we fully endorse the notion that humans are social animals. They seek groups and interact in social groups. The meta-analytic finding in favor of individual-self primacy invites a proposal regarding the relation between the individual and the group: A most critical function of the social group is to act as a protective mechanism that serves the needs of the individual (Greenberg, Solomon, \& Pyszczynski, 1997; Sedikides \& Skowronski, 2000, in press). We believe that theory and research are largely consistent with this proposal.

Social groups offer members information and meaning that reduce feelings of uncertainty (Hogg \& Mullin, 1999; Mullin \& Hogg, 1998). Social group membership is used strategically, at times, to buffer against harm to the individual self. Following an attack against the individual self, persons redefine themselves in terms of an accessible collective self (Cialdini et al., 1976; Gaertner et al., 1999; Mussweiler et al., 2000). Indeed, this shift to a collective self in the face of a threat to the individual self maintains psychological well being as assessed by mood state and state self-esteem (Mussweiler et al., 2000). Furthermore, employees regulate decisions to remain in or disengage from their social group (i.e., their corporation) depending predominantly on their personal gains (e.g., resources, satisfaction, opportunities for promotion) rather than company loyalty (Rusbult \& Farrell, 1983; Rusbult, Farrell, Rogers, \& Mainous, 1988). Similar effects have been demonstrated by a social hierarchy analysis of intergroup relations indicating that persons value their groups to the extent to which intragroup comparisons reflect positively on the individual self (Seta \& Seta, 1996). Collective action becomes more likely when discrimination against the in-group is perceived as an attack against the individual self (Foster \& Matheson, 1999). In a similar vein, minority groups (e.g., African Americans) appear to increase strategically the strength of their group identification as a response to threats to the individual self (Gray-Little \& Hafdahl, 2000).

At times, however, people behave in ways that are quite at odds with the tenets of the individual-self-primacy hypothesis. Persons fight voluntarily for their country and sacrifice their own lives to promote the welfare of their group. It is undeniable that the consequences of such behaviors benefit the group. Perhaps, as suggested in the section addressing caveats, these are situations to which individual-self primacy does not generalize. On the other hand, it is plausible that the motives underlying these groupserving behaviors are located in the individual self. Individual and collective welfare are often highly correspondent. Outcomes that harm the group may harm the individual, and outcomes that benefit the group may benefit the individual. For example, the demise of a country may entail the loss of personal freedoms. In a similar vein, acts that benefit the collective may be motivated by personal gains. Consistent with this line of reasoning are interviews with members of Palestinian martyrdom cults that reveal that suicide bombers are inspired to sacrifice their earthly bodies by the promise of bountiful rewards in heaven (Zwerdling, 1996).

Of course, we do not mean to imply that the collective self lacks motivational importance. The collective self is a vital part of self-definition and, therefore, plays an active role in the regulation of social behavior. We argue only that the individual self is relatively more fundamental than the collective (or the contextual, as it may be) self. People are indeed concerned with their group's welfare and act for the benefit of their group. However, such actions are likely curtailed to the extent to which they pose danger to the welfare of the individual self. Research by Gaertner and Insko (2000) provides a vivid example. Participants allocated more monetary resources to the in-group than to the out-group only in the case in which their own earnings could have been influenced by in-group members. That is, participants discriminated only when they could have maximized their earnings by reciprocating favorable allocations with in-group members. If participants were concerned with the enhancement of the collective self, they would have favored in-group members regardless of whether they were outcome dependent on other in-group or out-group members. This research is consistent with an individual-self-primacy analysis of intergroup discrimination, because the research locates the origin of intergroup discrimination in individual rather than collective motives.

\section{The Universality of Individual-Self Primacy: Culture as a Moderator?}

To what extent is the motivational primacy of the individual self a product of culture? Perspectives attesting to the cultural construction of the self (Heine, Lehman, Markus, \& Kitayama, 1999; Markus \& Kitayama, 1991) maintain that culture moderates the self-system. Individualistic (e.g., Western) cultures are characterized by loose ties among people and a concern for the rights and welfare of the person. Collectivistic (e.g., Eastern) cultures are characterized by strong ties among people, especially among ingroup members, and an obligation to maintain the welfare of the group. Such perspectives support the contextual-primacy hypothesis and suggest that individual-self primacy is limited to individualistic culture.

Consistent with the possibility of cultural moderation is research suggesting that the process of individual-self enhancement is absent in collectivistic culture (Heine et al., 1999). For example, Chen et al. (1998) showed that the tendency for group members to distance themselves psychologically from their group (as indexed by decreased levels of evaluative in-group favoritism) when the individual self experiences success and the collective self experiences failure is reduced in collectivistic culture. It is noteworthy, however, that members of collectivistic and individualistic culture did not differ in response to individual-self failure. ${ }^{2}$ In contrast to the cultural moderation perspective, an abundance of research reveals the dominant presence of the individual self in all cultures. This research has (a) used cross-cultural paradigms and (b) measured directly levels of collectivism and individualism.

In Japan and Thailand, self-enhancement has been detected on implicit measures. Letter and number evaluation tasks indicate a stronger preference for letters and numbers that occur in one's own name and birthdate, respectively (Hoorens, Nuttin, Erdelyi, Herman, \& Pavakanun, 1990; Kitayama \& Karasawa, 1997). Also, participants with interdependent self-construals (i.e., a self-concept that resembles the assumed prototypical self-concept of members of collectivistic cultures) exalt the individual self, as assessed by

\footnotetext{
${ }^{2}$ Unfortunately, we were unable to include in the meta-analysis effects from the experiment reported by Chen, Brockner, and Katz (1998). Success and failure feedback were explicitly and simultaneously directed to the individual self and collective self. This subsequently prevented us from calculating an effect size that registers the distinct response of each self.
} 
the Implicit Associations Test (Farnham, Greenwald, \& Banaji, 1999; Hetts, Sakuma, \& Pelham, 1999). In fact, interdependent self-construal participants defend and enhance the individual self even on explicit measures. Specifically, they elevate the individual self on interdependent traits (e.g., loyal), whereas participants with independent self-construals elevate the individual self on independent traits (e.g., leader; Sedikides, Gaertner, \& Toguchi, in press; see also Kurman, 2001).

It is interesting to note that, in individualistic and collectivistic cultures, willingness to provide to others (whether they be parents, siblings, cousins, close friends, acquaintances, or strangers) is related positively to expected reciprocation (Finjeman, Willemsen, $\&$ Poortinga, 1996). The operation of basic exchange principles, equity and reciprocity, indicates that even in collectivistic cultures there is an overwhelming concern for the welfare of the individual self. Additionally, a comparison of 55 nations has revealed that individual subjective well-being increases as a nation's level of individualism increases ( $r=.77$; Diener, Diener, \& Diener, 1995). This relation remains even when there is control for confounding variables (e.g., national differences in income, human rights violations, cultural heterogeneity). People are happier in a cultural context in which they can express freely the individual self.

Direct measurements of levels of collectivism and individualism also reveal the strong presence of the individual self among collectivistic persons. On self-description tasks, participants generate more aspects of their individual self than their collective self regardless of levels of collectivism and individualism (Gaertner et al., 1999, Investigation 4; Ybarra \& Trafimow, 1998, Experiment 3 ) and culture of origin (Trafimow et al., 1991). Furthermore, persons of color (i.e., African Americans, Asian Americans, and Latinos) score higher than do Anglos on measures of collectivism, yet they score just as high as Anglos on measures of individualism (Freeberg \& Stein, 1996; Gaines et al., 1997).

These research findings converge on a critical principle. Although level of collectivism is rather easily influenced by culture (e.g., norms), level of individualism is relatively invariant. Individualism is relatively immune to cultural variation. To us, this principle is yet another compelling indicator of the primacy of the individual self.

\section{Concluding Statements}

We engaged in comparative testing of three hypotheses, with a rather broad meta-theoretical agenda. We wanted to know which type of self is most valued subjectively and, thus, which self evokes the more intense responses to threat and enhancement. We wondered about the core of the human subjective experience, its selfness, or its psychological home base (Sedikides \& Gaertner, 2001b).

We conducted a meta-analytic synthesis of relevant research. We found that people react more strongly to threat and enhancement of the individual than collective self. This pattern is invariant of identification with the group, whether it be a minimal or a natural group. We take this finding as evidence of the motivational primacy of the individual self.

We wish, for a moment, to step beyond the limits of the data and ask whether the contextual approach has committed an inferential fallacy. On the basis of evidence suggesting that the self responds flexibly to contextual influences, this approach has concluded that the essence of the self is contextual. Such an inference may be unwarranted. Extrapolating beyond the current findings, we offer a contrasting view: The individual self is a stable system that can react flexibly to contextual influences.

We are in agreement with Simon and Kampmeier's (2001) observation that "while the collective self has moved up to a more prominent position on social psychologists' research agenda, it appears that the individual self simply has been taken for granted" (p. 200). Indeed, we view the findings of this meta-analysis, first and foremost, as a justification, if not a rationale or even a challenge, for researchers to place a greater emphasis on the individual self when engaging in theory building. The individual self deserves serious consideration as a cornerstone of theory building, especially as far as its motivational facets are concerned.

Obviously, a group-level analysis is necessary for an understanding of some social phenomena. Likewise, using the group as the unit of analysis is sufficient for an understanding of other intergroup and intragroup processes (Sedikides, Schopler, \& Insko, 1998). However, we believe that researchers will often gain valuable insight by reviewing several well-established phenomena or processes, or by conceptualizing novel ones, from the perspective of the individual self (Aron \& McLaughlin-Volpe, 2001; E. R. Smith \& Henry, 1996; E. R. Smith, Murphy, \& Coates, 1999). This is especially likely when motivational facets of the individual self are involved. Above all, we hope that our meta-analytic synthesis contributes to the planning of primary-level experiments (Eagly \& Wood, 1994) that will subject the issue of motivational primacy to further empirical scrutiny.

\section{References}

References marked with an asterisk indicate studies included in the meta-analysis.

Abrams, D. (1994). Social self-regulation. Personality and Social Psychology Bulletin, 20, 473-483.

Abrams, D., \& Hogg, M. (1990). Social identity theory: Constructive and critical advances. New York: Springer-Verlag.

Abrams, D., \& Hogg, M. (Eds.). (1999). Social identity and social cognition. Oxford, England: Blackwell.

Andersen, S. M. (1984). Self-knowledge and social inference: II. The diagnosticity of cognitive/affective and behavioral data. Journal of Personality and Social Psychology, 46, 294-307.

Andersen, S. M., Glassman, N. S., \& Gold, D. A. (1998). Mental representations of the self, significant others, and nonsignificant others: Structure and processing of private and public aspects. Journal of Personality and Social Psychology, 75, 845-861.

Andersen, S. M., Lazowski, L. E., \& Donisi, M. (1986). Salience and self-inference: The role of biased recollections in self-inference processes. Social Cognition, 4, 75-95.

Aron, A., \& McLaughlin-Volpe, T. (2001). Including others in the self: Extension to own and partner's group memberships. In C. Sedikides \& M. B. Brewer (Eds.), Individual self, relational self, collective self (pp. 89-108). Philadelphia: Psychology Press.

Barr, S. H., \& Conlon, E. J. (1994). Effects of distribution of feedback in work groups. Academy of Management Journal, 37, 641-655.

Baumeister, R. F. (1991). Escaping the self: Alcoholism, spirituality, masochism, and other flights from the burden of selfhood. New York: Basic Books.

Baumeister, R. F., Bratslavsky, E., Finkenauer, C., \& Vohs, K. D. (2001). Bad is stronger than good. Review of General Psychology, 5, 323-370.

Baumeister, R. F., \& Jones, E. E. (1978). When self-presentation is constrained by the target's knowledge: Consistency and compensation. Journal of Personality and Social Psychology, 36, 405-417. 
Bem, D. J., \& Allen, A. (1974). On predicting some of the people some of the time: The search for cross-situational consistencies in behavior. Psychological Review, 81, 506-520.

*Biernat, M., Vescio, T. K., \& Green, M. L. (1996). Selective selfstereotyping. Journal of Personality and Social Psychology, 71, 11941209.

Blaine, B., \& Crocker, J. (1993). Self-esteem and self-serving biases in reactions to positive and negative events: An integrative review. In R. F. Baumeister (Ed.), Self-esteem: The puzzle of low self-regard (pp. 5585). New York: Plenum Press.

Block, J. (1961). Ego-identity, role variability, and adjustment. Journal of Consulting and Clinical Psychology, 25, 392-397.

Blumer, H. (1969). Symbolic interactionism: Perspectives and methods. Englewood Cliffs, NJ: Prentice Hall.

Branscombe, N. R., \& Wann, D. L. (1994). Collective self-esteem consequences of outgroup derogation when a valued social identity is on trial. European Journal of Social Psychology, 24, 641-658.

Brewer, M. B. (1991). The social self: On being the same and different at the same time. Personality and Social Psychology Bulletin, 17, 475482.

Brewer, M. B., \& Caporael, L. R. (1990). Selfish genes vs. selfish people: Sociobiology as origin myth. Motivation and Emotion, 14, 237-243.

Brewer, M. B., \& Gardner, W. (1996). Who is this "we"? Levels of collective identity and self representations. Journal of Personality and Social Psychology, 71, 83-93.

Brewer, M. B., \& Roccas, S. (2001). Individual values, social identity, and optimal distinctiveness. In C. Sedikides \& M. B. Brewer (Eds.), Individual self, relational self, collective self (pp. 219-237). Philadelphia: Psychology Press.

Bulmer, M. G. (1978). Group selection in structured populations. American Naturalist, 112, 389-399.

Cadinu, M. R., \& Cerchioni, M. (2001). Compensatory biases after ingroup threat: "Yeah, but we have a good personality." European Journal of Social Psychology, 31, 353-367.

*Cadinu, M. R., \& Rothbart, M. (1996). Self-anchoring and differentiation processes in the minimal group setting. Journal of Personality and Social Psychology, 70, 661-677.

Campbell, J. D., Trapnell, P. D., Heine, S. J., Katz, I. M., Lavallee, L. F., \& Lehman, D. R. (1996). Self-concept clarity: Measurement, personality correlates, and cultural boundaries. Journal of Personality and Social Psychology, 70, 141-156.

Campbell, K. W., \& Sedikides, C. (1999). Self-threat magnifies the selfserving bias: A meta-analytic integration. Review of General Psychology, 3, 23-43.

Cantor, N., Markus, H., Niedenthal, P., \& Nurius, P. (1986). On motivation and the self-concept. In R. M. Sorrentino \& E. T. Higgins (Eds.), Motivation and cognition: Foundations of social behavior (pp. 96-127). New York: Guilford Press.

Caporael, L. R. (1997). The evolution of truly social cognition: The core configurations model. Personality and Social Psychology Review, 1, 276-298.

Caporael, L. R., \& Baron, R. M. (1997). Groups as the mind's natural environment. In J. Simpson \& D. Kenrick (Eds.), Evolutionary social psychology (pp. 317-343). Hillsdale, NJ: Erlbaum.

Carver, C. S., \& Scheier, M. F. (1998). On the self-regulation of behavior. New York: Cambridge University Press.

Caspi, A., \& Roberts, B. W. (2001). Personality development across the life course: The argument for change and continuity. Psychological Inquiry, 12, 49-66.

Chen, Y., Brockner, J., \& Katz, T. (1998). Toward an explanation of cultural differences in in-group favoritism: The role of individual versus collective primacy. Journal of Personality and Social Psychology, 75, 1490-1502.

Cialdini, R. B., Borden, R. J., Thorne, A., Walker, M. R., Freeman, S., \&
Sloan, L. R. (1976). Basking in reflected glory: Three (football) field studies. Journal of Personality and Social Psychology, 34, 366-375.

Cooley, C. H. (1902). Human nature and the social order. New York: Scribner.

Crocker, J., \& Major, B. (1989). Social stigma and self-esteem: The self-protective properties of stigma. Psychological Review, 96, 608630.

Crocker, J., Voelki, K., Testa, M., \& Major, B. (1991). Social stigma: The affective consequences of attributional ambiguity. Journal of Personality and Social Psychology, 60, 218-228.

Crosby, F. (1984). The denial of personal discrimination. American Behavioral Scientist, 27, 371-386.

Damon, W., \& Hart, D. (1986). Stability and change in children's selfunderstanding. Social Cognition, 4, 102-118.

Dawkins, R., \& Krebs, J. R. (1978). Animal signals: Information or manipulation? In J. R. Krebs \& N. B. Davies (Eds.), Behavioral ecology (pp. 282-309). Oxford, England: Blackwell.

Deaux, K. (1996). Social identification. In E. T. Higgins \& A. Kruglanski (Eds.), Social psychology: Handbook of basic principles (pp. 777-798). New York: Guilford Press.

Deaux, K., \& Perkins, T. S. (2001). The kaleidoscopic self. In C. Sedikides $\&$ M. B. Brewer (Eds.), Individual self, relational self, collective self (pp. 299-313). Philadelphia: Psychology Press.

deBary, W. T. (1979). Sagehood as a secular and spiritual ideal in Tokugawa neo-Confucianism. In W. T. deBary \& I. Bloom (Eds.), Principle and practicality: Essays on neo-Confucianism and practical learning. New York: Columbia University Press.

Deci, E. L., \& Ryan, R. M. (2000). The "what" and "why" of goal pursuits: Human needs and the self-determination of behavior. Psychological Inquiry, 11, 227-268.

Deutsch, F. M., Ruble, D. N., Brooks-Gunn, J., Flemming, A., \& Stangor, C. (1988). Information-seeking and material self-definition during the transition to motherhood. Journal of Personality and Social Psychology, 55, 420-431.

Diener, E., Diener, M., \& Diener, C. (1995). Factors predicting the subjective well-being of nations. Journal of Personality and Social Psychology, 69, 851-864.

*Duck, J. M., Hogg, M. A., \& Terry, D. J. (1995). Me, us and them: Political identification and the third-person effect in the 1993 Australian federal election. European Journal of Social Psychology, 25, 195-215.

Dunning, D. (1999). A newer look: Motivated social cognition and the schematic representation of social concepts. Psychological Inquiry, 10, $1-11$.

Durkheim, E. (1950). The rule of sociological method. New York: Free Press.

Eagly, A. H., \& Wood, W. (1994). Using research syntheses to plan future research. In H. Cooper \& L. Hedges (Eds.), The handbook of research synthesis (pp. 485-500). New York: Russell Sage Foundation.

Ellemers, N., van Knippenberg, A., de Vries, N., \& Wilke, H. (1988). Social identification and permeability of group boundaries. European Journal of Social Psychology, 18, 497-513.

Ellemers, N., van Knippenberg, A., \& Wilke, H. (1990). The influence of permeability of group boundaries and stability of group status on strategies of individual mobility and social change. British Journal of Social Psychology, 29, 233-246.

Emmons, R. A. (1986). Personal strivings: An approach to personality and subjective well-being. Journal of Personality and Social Psychology, 51, $1058-1068$.

Farnham, S. D., Greenwald, A. G., \& Banaji, M. R. (1999). Implicit self-esteem. In D. Abrams \& M. A. Hogg (Eds.), Social identity and social cognition (pp. 230-248). Oxford, England: Blackwell.

Field, A. P. (2001, March). Fixed-effects models of meta-analysis for real-world data: A brief simulation. Paper presented at the meeting of the British Psychological Society, Glasgow, Scotland.

Finjeman, Y. A., Willemsen, M. E., \& Poortinga, Y. H. (1996). Individu- 
alism-collectivism: An empirical study of a conceptual issue. Journal of Cross Cultural Psychology, 27, 381-402.

Foster, M. D., \& Matheson, K. (1999). Perceiving and responding to the personal/group discrimination discrepancy. Personality and Social Psychology Bulletin, 25, 1319-1329.

Freeberg, A. L., \& Stein, C. H. (1996). Felt obligation towards parents in Mexican-American and Anglo-American young adults. Journal of Social and Personal Relationships, 14, 457-471.

Gaertner, L., \& Insko, C. A. (2000). Intergroup discrimination in the minimal group paradigm: Categorization, reciprocation, or fear? Journal of Personality and Social Psychology, 79, 77-94.

*Gaertner, L., Sedikides, C., \& Graetz, K. (1999). In search of selfdefinition: Motivational primacy of the individual self, motivational primacy of the collective self, or contextual primacy? Journal of Personality and Social Psychology, 76, 5-18.

Gaines, S. O., Jr., Marelich, W. D., Bledsoe, W., Steers, W. N., Henderson, M. C., Granrose, C. S., et al. (1997). Links between race/ethnicity and cultural values as mediated by racial/ethnic identity and moderated by gender. Journal of Personality and Social Psychology, 72, 1460-1476.

Gould, S. J. (1981). The mismeasure of man. New York: Norton.

*Graetz, K. A. (1992). Anger over group mistreatment: An application of the intergroup schema. Unpublished doctoral dissertation, University of North Carolina at Chapel Hill.

Gramzow, R. H., Gaertner, L., \& Sedikides, C. (2001). Memory for ingroup and outgroup information in a minimal group context: The self as an informational base. Journal of Personality and Social Psychology, 80, 188-205.

Gramzow, R. H., Sedikides, C., Panter, A. T., \& Insko, C. A. (2000). Aspects of self-regulation and self-structure as predictors of perceived emotional distress. Personality and Social Psychology Bulletin, 26, $188-206$.

Gray-Little, B., \& Hafdahl, A. R. (2000). Factors influencing racial comparisons of self-esteem: A quantitative review. Psychological Bulletin, 126, 26-54.

Green, J. D., \& Sedikides, C. (2001). When do self-schemas shape social perception?: The role of descriptive ambiguity. Motivation and Emotion, 25, 67-83.

Greenberg, J., \& Pyszczynski, T. (1985). Compensatory self-inflation: A response to the threat to self-regard of public failure. Journal of Personality and Social Psychology, 49, 273-280.

Greenberg, J., Solomon, S., \& Pyszczynski, T. (1997). Terror management theory of self-esteem and cultural worldviews: Empirical assessments and cultural refinements. In M. Zanna (Ed.), Advances in experimental social psychology (Vol. 29, pp. 61-139). San Diego, CA: Academic Press.

Greenwald, A. G. (1980). The totalitarian ego: Fabrication and revision of personal history. American Psychologist, 35, 603-618.

Hedges, L. V., \& Olkin, I. (1985). Statistical methods for meta-analysis. San Diego, CA: Academic Press.

Hedges, L. V., \& Vevea, J. L. (1998). Fixed- and random-effects models in meta-analysis. Psychological Methods, 3, 486-504.

Heine, S. J., Lehman, D. R., Markus, H. R., \& Kitayama, S. (1999). Is there a universal need for positive self-regard? Psychological Review, 106, 766-794.

Hetts, J. J., Sakuma, M., \& Pelham, B. W. (1999). Two roads to positive regard: Implicit and explicit self-evaluation and culture. Journal of Experimental Social Psychology, 35, 512-559.

Higgins, E. T. (1996). The "self digest": Self-knowledge serving selfregulatory functions. Journal of Personality and Social Psychology, 71, 1062-1083.

Higgins, E. T., \& May, D. (2001). Individual self-regulatory functions: It's not "we" regulation, but it's still social. In C. Sedikides \& M. B. Brewer (Eds.), Individual self, relational self, collective self (pp. 47-67). Philadelphia: Psychology Press.

Hirt, E. R., Zillman, D., Erickson, G. A., \& Kennedy, C. (1992). Costs and benefits of allegiance: Changes in fans' self-ascribed competencies after team victory versus defeat. Journal of Personality and Social Psychology, 63, 724-738.

Hogg, M. A., \& Mullin, B. A. (1999). Joining groups to reduce uncertainty: Subjective uncertainty reduction and group identification. In D. Abrams \& M. A. Hogg (Eds.), Social identity and social cognition (pp. 249279). Oxford, England: Blackwell.

Hogg, M. A., \& Turner, J. C. (1987). Intergroup behavior, self-stereotyping and the salience of social categories. British Journal of Social Psychology, 26, 325-340.

Hoorens, V., Nuttin, J. M., Erdelyi, M., Herman, I., \& Pavakanun, U. (1990). Mastery pleasure versus mere ownership: A quasi-experimental cross-cultural and cross-alphabetic test of the name letter effect. European Journal of Social Psychology, 20, 181-205.

Huntington, S. P. (1993). The clash of civilization. Foreign Affairs, 72, $22-49$.

Ito, T. A., Larsen, J. T., Smith, N. K., \& Cacioppo, J. T. (1998). Negative information weighs more heavily on the brain: The negativity bias in evaluative categorizations. Journal of Personality and Social Psychology, 75, 887-900.

Jackson, L. A., Sullivan, L. A., Harnish, R., \& Hodge, C. N. (1996). Achieving positive social identity: Social mobility, social creativity, and permeability of group boundaries. Journal of Personality and Social Psychology, 70, 241-254.

*Jaffe, Y., \& Yinon, Y. (1979). Retaliatory aggression in individuals and groups. European Journal of Social Psychology, 9, 177-186.

James, W. (1983). The principles of psychology. Cambridge, MA: Harvard University Press. (Original work published 1890)

Kahneman, D., \& Tversky, A. (1979). Prospect theory: An analysis of decision under risk. Econometrica, 47, 263-291.

Kawakami, K., \& Dion, K. L. (1993). The impact of salient self-identities on relative deprivation and action intentions. European Journal of Social Psychology, 23, 525-540.

Kenny, D. A., \& DePaulo, B. M. (1993). Do people know how others view them? An empirical and theoretical account. Psychological Bulletin, $114,145-161$.

Kessler, T., Mummendey, A., \& Leisse, U. (2000). The personal-group discrepancy: Is there a common information basis for personal and group judgment? Journal of Personality and Social Psychology, 79, 95-109.

Kitayama, S., \& Karasawa, M. (1997). Implicit self-esteem in Japan: Name letters and birthday numbers. Personality and Social Psychology Bulletin, 23, 736-742.

Klein, S. B. (2001). A self to remember: A cognitive neuropsychological perspective on how self creates memory and memory creates self. In C. Sedikides \& M. B. Brewer (Eds.), Individual self, relational self, collective self (pp. 25-46). Philadelphia: Psychology Press.

Krueger, J. (2000). The projective perceptions of the social world: A building block of social comparison processes. In J. Suls \& L. Wheeler (Eds.), Handbook of social comparison: Theory and research (pp. 323351). New York: Kluwer Academic/Plenum Publishers.

Kurman, J. (2001). Self-enhancement: Is it restricted to individualistic cultures? Personality and Social Psychology Bulletin, 12, 1705-1716.

Lakatos, I. (1970). Falsification and the methodology of scientific research programmes. In I. Lakatos \& A. Musgrave (Eds.), Criticism and the growth of knowledge (pp. 91-196). London: Cambridge University Press.

Lalonde, R. (1992). The dynamics of group differentiation in the face of defeat. Personality and Social Psychology Bulletin, 18, 336-342.

Lewis, M. (2001). Issues in the study of personality development. Psychological Inquiry, 12, 67-83.

*Lindeman, M. (1997). Ingroup bias, self-enhancement and group identification. European Journal of Social Psychology, 27, 337-355.

*Lindeman, M., \& Sundvik, L. (1995). Evaluative bias and selfenhancement among gender groups. European Journal of Social Psychology, 27, 269-280. 
Linville, P. W. (1982). The complexity-extremity effect and age-based stereotyping. Journal of Personality and Social Psychology, 42, 193-211.

Linville, P. W., Fischer, G. W., \& Salovey, P. (1989). Perceived distributions of the characteristics of ingroup and outgroup members: Empirical evidence and a computer simulation. Journal of Personality and Social Psychology, 57, 165-188.

Linville, P. W., Fischer, G. W., \& Yoon, C. (1996). Perceived covariation among the features of ingroup and outgroup members: The outgroup covariation effect. Journal of Personality and Social Psychology, 70, 421-436.

Little, B. R. (1983). Personal projects: A rationale and method for investigation. Environment and Behavior, 15, 273-309.

*Long, K. M., \& Spears, R. (1998). Opposing effects of personal and collective self-esteem on interpersonal and intergroup comparisons. European Journal of Social Psychology, 29, 913-930.

Macfarlane, A. (1978). The origins of English individualism: The family, property, and social transition. New York: Cambridge University Press.

Mahoney, M. J. (1977). Publication prejudices: An experimental study of confirmatory bias in the peer review system. Cognitive Therapy and Research, 1, 161-175.

Markus, H. (1977). Self-schemata and processing information about the self. Journal of Personality and Social Psychology, 35, 63-78.

Markus, H., \& Kitayama, S. (1991). Culture and the self: Implications for cognition, emotion, and motivation. Psychological Review, 98, 224-253.

Markus, H., \& Kunda, Z. (1986). Stability and malleability of the selfconcept. Journal of Personality and Social Psychology, 51, 858-866.

Markus, H., \& Nurius, P. (1986). Possible selves. American Psychologist, 41, 954-969.

Markus, H., \& Wurf, E. (1987). The dynamic self-concept: A social psychological perspective. Annual Review of Psychology, 38, 299-337.

McCrae, R. R., \& Costa, P. T. (1994). The stability of personality: Observation and evaluations. Current Directions in Psychological Science, 3, 173-175.

McFarland, C., \& Buehler, R. (1995). Collective self-esteem as a moderator of the frog-pond effect in reactions to performance feedback. Journal of Personality and Social Psychology, 68, 1055-1070.

Mead, G. H. (1934). Mind, self, and society. Chicago: University of Chicago Press.

Miller, D. T. (1999). The norm of self-interest. American Psychologist, 54, 1053-1060.

Moghaddam, F. M., Stolkin, A. J., \& Hutcheson, L. S. (1997). A generalized personal/group discrepancy: Testing domain specificity of a perceived higher effect of events on one's group than on oneself. Personality and Social Psychology Bulletin, 23, 743-750.

Mortimer, J. T., Finch, M. D., \& Kumka, D. (1982). Persistence and change in development: The multidimensional self-concept. In P. B. Baltes \& O. G. Brim, Jr. (Eds.), Life-span development and behavior (Vol. 4, pp. 263-312). New York: Academic Press.

Mullin, B. A., \& Hogg, M. A. (1998). Dimensions of subjective uncertainty in social identification and minimal intergroup discrimination. British Journal of Social Psychology, 37, 345-365.

Mussweiler, T., Gabriel, S., \& Bodenhausen, G. V. (2000). Shifting social identities as a strategy for deflecting threatening social comparisons. Journal of Personality and Social Psychology, 79, 398-409.

National Research Council. (1992). Combining information: Statistical issues and opportunities for research. Washington, DC: National Academy Press.

Ostrom, T. M., Carpenter, S. L., Sedikides, C., \& Li, F. (1993). Differential processing of in-group and out-group information. Journal of Personality and Social Psychology, 64, 21-34.

Ostrom, T. M., \& Sedikides, C. (1992). Out-group homogeneity effects in natural and minimal groups. Psychological Bulletin, 112, 536-552.

Otten, S., \& Wentura, D. (2001). Self-anchoring and in-group favoritism: An individual profiles analysis. Journal of Experimental Social Psychology, 37, 525-532.
Pelham, B. W. (1991). On confidence and consequence: The certainty and importance of self-knowledge. Journal of Personality and Social Psychology, 60, 518-530.

Pelham, B. W., \& Wachsmuth, J. O. (1995). The waxing and waning of the social self: Assimilation and contrast in social comparison. Journal of Personality and Social Psychology, 69, 825-838.

Platt, J. R. (1964). Strong inference. Science, 146, 347-353.

Prentice, D. A. (1990). Familiarity and differences in self- and otherrepresentations. Journal of Personality and Social Psychology, 59, 369383.

Reid, A., \& Deaux, K. (1996). Relation between social and personal identities: Segregation or integration. Journal of Personality and Social Psychology, 71, 1084-1091.

Rogers, K. (Ed.). (1997). Self-interest: An anthology of philosophical perspectives. New York: Routledge.

Rosenthal, R. (1966). Experimenter effects in behavioral research. New York: Appleton.

Rozin, P., \& Royzman, E. B. (2001). Negativity bias, negativity dominance, and contagion. Personality and Social Psychology Review, 5, 296-320.

Rusbult, C. E., \& Farrell, D. (1983). A longitudinal test of the investment model: The impact on job satisfaction, job commitment, and turnover of variations in rewards, costs, alternatives, and investments. Journal of Applied Psychology, 68, 429-438.

Rusbult, C. E., Farrell, D., Rogers, G., \& Mainous, A. G., III. (1988). Impact of exchange variables on exit, voice, loyalty, and neglect: An integrative model of responses to declining job satisfaction. Academy of Management Journal, 31, 599-627.

Ryen, A. H., \& Kahn, A. (1975). Effects of intergroup orientation on group attitudes and proxemic behavior. Journal of Personality and Social Psychology, 31, 302-310.

Schuerger, J. M., Tait, E., \& Tavernelli, M. (1982). Temporal stability of personality by questionnaire. Journal of Personality and Social Psychology, 43, 176-182.

Sedikides, C. (1995). Central and peripheral self-conceptions are differentially influenced by mood: Tests of the differential sensitivity hypothesis. Journal of Personality and Social Psychology, 69, 759-777.

Sedikides, C., \& Brewer, M. B. (Eds.). (2001). Individual self, relational self, collective self. Philadelphia: Psychology Press.

Sedikides, C., Campbell, W. K., Reeder, G., Elliot, A. J., \& Gregg, A. P. (2002). Do others bring out the worst in narcissists? The "others exist for me" illusion. In Y. Kashima, M. Foddy, \& M. Platow (Eds.), Self and identity: Personal, social, and symbolic (pp. 103-123). Mahwah, NJ: Erlbaum.

Sedikides, C., \& Gaertner, L. (2001a). A homecoming to the individual self: Emotional and motivational primacy. In C. Sedikides \& M. F. Brewer (Eds.), Individual self, relational self, collective self (pp. 7-23). Philadelphia: Psychology Press.

Sedikides, C., \& Gaertner, L. (2001b). The social self: The quest for identity and the motivational primacy of the individual self. In J. P. Forgas, K. D. Williams, \& L. Wheeler (Eds.), The social mind: Cognitive and motivational aspects of interpersonal behavior (pp. 115-138). Cambridge, England: Cambridge University Press

Sedikides, C., Gaertner, L., \& Toguchi, Y. (in press). Pancultural selfenhancement. Journal of Personality and Social Psychology.

Sedikides, C., \& Green, J. D. (2000). On the self-protective nature of inconsistency/negativity management: Using the person memory paradigm to examine self-referent memory. Journal of Personality and Social Psychology, 79, 906-922.

Sedikides, C., Schopler, J., \& Insko, C. A. (Eds.). (1998). Intergroup cognition and intergroup behavior. Mahwah, NJ: Erlbaum.

Sedikides, C., \& Skowronski, J. J. (1993). The self in impression formation: Trait centrality and social perception. Journal of Experimental Social Psychology, 29, 347-357. 
Sedikides, C., \& Skowronski, J. J. (1997). The symbolic self in evolutionary context. Personality and Social Psychology Review, 1, 89-102.

Sedikides, C., \& Skowronski, J. J. (2000). On the evolutionary functions of the symbolic self: The emergence of self-evaluation motives. In A. Tesser, R. Felson, \& J. Suls (Eds.), Psychological perspectives on self and identity (pp. 91-117). Washington, DC: American Psychological Association.

Sedikides, C., \& Skowronski, J. J. (in press). Evolution of the self: Issues and prospects. In M. R. Leary \& J. P. Tangney (Eds.), Handbook of self and identity. New York: Guildford Press.

Sedikides, C., \& Strube, M. J. (1997). Self-evaluation: To thine own self be good, to thine own self be sure, to thine own self be true, and to thine own self be better. In M. P. Zanna (Ed.), Advances in experimental social psychology (Vol. 29, pp. 209-269). New York: Academic Press.

Seta, J. J., \& Seta, C. E. (1996). Big fish in small ponds: A social hierarchy analysis of intergroup bias. Journal of Personality and Social Psychology, 71, 1210-1221.

Simon, B. (1997). Self and group in modern society: Ten theses on the individual self and the collective self. In R. Spears, P. J. Oakes, N. Ellemers, \& S. A. Haslam (Eds.), The social psychology of stereotyping and group life (pp. 318-335). Oxford, England: Blackwell.

Simon, B., \& Hastedt, C. (1999). Self-aspects as social categories: The role of personal importance and valence. European Journal of Social Psychology, 29, 479-487.

Simon, B., \& Kampmeier, C. (2001). Revisiting the individual self: Toward a social psychological theory of the individual self and the collective self. In C. Sedikides \& M. B. Brewer (Eds.), Individual self, relational self, collective self (pp. 199-218). Philadelphia: Psychology Press.

Simon, B., Pantaleo, G., \& Mummendey, A. (1995). Unique individual or interchangeable group member? The accentuation of intragroup differences versus similarities as an indicator of the individual self versus the collective self. Journal of Personality and Social Psychology, 69, 106119.

Smith, E. R., \& Henry, S. (1996). An ingroup becomes part of the self: Response time evidence. Personality and Social Psychology Bulletin, 22, 635-642.

Smith, E. R., Murphy, J., \& Coates, S. (1999). Attachment to groups: Theory and measurement. Journal of Personality and Social Psychology, 77, 94-110.

Smith, H. J., \& Spears, R. (1996). Ability and outcome evaluations as a function of personal and collective (dis)advantage: A group escape from individual bias. Personality and Social Psychology Bulletin, 22, 690704.

Smith, H. J., Spears, R., \& Oyen, M. (1994). "People like us:" The influence of personal deprivation and group membership salience on justice evaluations. Journal of Experimental Social Psychology, 30, 277-299.

Sober, E. (1980). Holism, individualism and the units of selection. Philosophy of Science Association, 2, 93-121.

Spears, R. (2001). The interaction between the individual and the collective self: Self-categorization in context. In C. Sedikides \& M. B. Brewer (Eds.), Individual self, relational self, collective self (pp. 171-198). Philadelphia: Psychology Press.

Spears, R., Doosje, B., \& Ellemers, N. (1997). Self-stereotyping in the face of threats to group status and distinctiveness: The role of group identification. Personality and Social Psychology Bulletin, 23, 538-553.

Steele, C. M. (1988). The psychology of self-affirmation: Sustaining the integrity of the self. In L. Berkowitz (Ed.), Advances in experimental social psychology (Vol. 21, pp. 181-227). San Diego, CA: Academic Press.

Swann, W. B. (1990). To be adored or to be known? The interplay of self-enhancement and self-verification. In E. T. Higgins \& R. M. Sorrentino (Eds.), Handbook of motivation and cognition: Foundations of social behavior (Vol. 2, pp. 408-448). New York: Guilford Press.
Tajfel, H. (1969). Cognitive aspects of prejudice. Journal of Social Issues, 25, 79-97.

Tajfel, H. (1982). Social identity and intergroup relations. Cambridge, England: Cambridge University Press.

Tajfel, H., \& Turner, J. C. (1979). An integrative theory of intergroup conflict. In W. G. Austin \& S. Worchel (Eds.), The social psychology of intergroup relations (pp. 33-47). Monterey, CA: Brooks/Cole.

Taylor, D. M., Wright, S. C., Moghaddam, F. M., \& Lalonde, R. N. (1990). The personal/group discrimination discrepancy: Perceiving my group, but not myself, to be a target of discrimination. Personality and Social Psychology Bulletin, 16, 254-262.

Taylor, S. E. (1991). Asymmetrical effects of positive and negative events: The mobilization-minimization hypothesis. Psychological Bulletin, 110, 67-85.

Taylor, S. E., \& Brown, J. D. (1988). Illusion and well-being: A social psychological perspective on mental health. Psychological Bulletin, 103, 193-210.

Tesser, A. (2000). On the confluence of self-esteem maintenance mechanisms. Personality and Social Psychology Review, 4, 290-299.

Tindale, R. S., Kulik, C. T., \& Scott, L. A. (1991). Individual and group feedback and performance: An attributional perspective. Basic and Applied Social Psychology, 12, 41-62.

Trafimow, D., Triandis, H. C., \& Goto, S. G. (1991). Some tests of the distinction between the private self and the collective self. Journal of Personality and Social Psychology, 60, 649-655.

Triandis, H. C. (1995). Individualism and collectivism. Boulder, CO: Westview Press.

Triandis, H. C., \& Trafimow, D. (2001). Cross-national prevalence of collectivism. In C. Sedikides \& M. B. Brewer (Eds.), Individual self, relational self, collective self (pp. 259-276). Philadelphia: Psychology Press.

Turner, J. C., Hogg, M. A., Oakes, P. J., Reicher, S. D., \& Wetherell, M. S. (1987). Rediscovering the social group: A self-categorization theory. Oxford, England: Blackwell.

Turner, J. C., Oakes, P. J., Haslam, S. A., \& McGarty, C. (1994). Self and collective: Cognition and social context. Personality and Social Psychology Bulletin, 20, 454-463.

Tyler, T. R., Kramer, R., \& John, O. (1999). The psychology of the social self. Hillsdale, NJ: Erlbaum.

Tversky, A., \& Kahneman, D. (1986). Rational choice and the framing of decisions. Journal of Business, 59, 251-278.

Vevea, J. L., \& Hedges, L. V. (1995). A general linear model for estimating effect size in the presence of publication bias. Psychometrika, 60, 419-435.

Wallace, B. (1973). Misinformation, fitness, and selection. American Naturalist, 107, 1-7.

Weber, M. (1964). Basic concepts in sociology. New York: Citadel Press.

Westfall, R. S. (1973). Newton and the fudge factor. Science, 179, 751758.

Wicklund, R. A., \& Gollwitzer, P. M. (1982). Symbolic self-completion. Hillsdale, NJ: Erlbaum.

Wiebe, D. J. (1991). Hardiness and stress moderation: A test of proposed mechanisms. Journal of Personality and Social Psychology, 60, 89-99.

Wilson, D. S., \& Sober, E. (1994). Reintroducing group selection to the human behavioral sciences. Behavioral and Brain Sciences, 17, 585654.

Ybarra, O., \& Trafimow, D. (1998). How priming the private self or collective self affects the relative weights of attitudes and subjective norms. Personality and Social Psychology Bulletin, 24, 362-370.

Zwerdling, D. (1996, March 9). Weekend All Things Considered: Suicide bombers [Radio broadcast]. Washington, DC: National Public Radio.

Received December 21, 2001

Revision received January 22, 2002

Accepted January 30, 2002 